\section{Homogenisation improves the microstructure, syneresis and rheological properties of} buffalo yoghurt

\author{
Hanh T.H Nguyen ${ }^{\text {a,b }}$, Lydia Ong ${ }^{\text {a,b }}$, Sandra E. Kentish ${ }^{\text {a }}$ and Sally L. Gras ${ }^{\text {a,b* }}$
}

${ }^{a}$ The ARC Dairy Innovation Hub, Department of Chemical and Biomolecular Engineering, The University of Melbourne, Parkville, Victoria 3010, Australia.

${ }^{b}$ The Bio21 Molecular Science and Biotechnology Institute, The University of Melbourne, Parkville, Victoria 3010, Australia.

*Corresponding author: The Bio21 Molecular Science and Biotechnology Institute, The University of Melbourne, Parkville, Victoria 3010, Australia. Tel.: +61 38344 6281; fax: +61 3 8344 4153. E-mail address: sgras@unimelb.edu.au

\title{
ABSTRACT
}

(1)

Homogenisation is known to improve the textural properties of bovine yoghurt but the potential of this processing step has not been systematically explored for buffalo yoghurt. In this study, buffalo milk was homogenised at 80 bar or 160 bar and the effect on the properties of buffalo yoghurt examined. The microstructure of both buffalo yoghurt samples produced from homogenised milk was significantly altered, forming a more interconnected protein network with smaller embedded fat globules. These structural changes resulted in a significant decrease in syneresis and hysteresis area and led to a considerable increase in the storage modulus, gel firmness and flow behavior index. A higher homogenisation pressure of 160 bar resulted in a lower gel firmness and storage modulus, possibly due to the presence of bigger fat-protein clusters within the homogenised milk. These results suggest that a homogenisation pressure of 80 bar could be optimal for improving the quality of buffalo yoghurt. 


\section{Introduction}

Yoghurt is a semi-solid food with a microstructure consisting of a protein network, in which fat globules are integrated (Lucey \& Singh, 1997; Sodini, Remeuf, Haddad, \& Corrieu, 2004). This microstructure and the rheological properties of yoghurt are critical to product quality, as they directly link to desirable functional and sensory properties including the smoothness, firmness and flowability (Lee \& Lucey, 2003; Rao \& Lopes da Silva, 2007). These properties can be controlled by careful selection of the ingredients, such as the milk source and concentration of milk solids, starter culture, additives and processing conditions.

In the production of bovine yoghurt, the milk is often subjected to homogenisation at pressures of 100-200 bar at 55-65 ${ }^{\circ} \mathrm{C}$ (Chandan \& O'Rell, 2006; Lucey \& Singh, 1997). Under these pressures, the integrity of the casein micelles is maintained, while the fat globules are significantly affected. These changes include the creation of smaller fat globules with an increased surface area that is partly or entirely coated with absorbed casein and denatured whey protein (Michalski, Cariou, Michel, \& Garnier, 2002; Ong, Dagastine, Kentish, \& Gras, 2010; Sameen, Anjum, Huma, \& Nawaz, 2010). The adsorbed proteins are incorporated in the gel network during acid induced coagulation and can lead to a number of improvements in yoghurt production, including a better texture, decreased whey separation, increased gel firmness and better integration of fat globules (Tamime \& Robinson, 2007).

Buffalo yoghurt is typically made with unhomogenised milk (Tamime \& Robinson, 2007). This results in a yoghurt that exhibits greater syneresis and a larger hysteresis area than bovine yoghurt (Nguyen, Ong, Lefevre, Kentish, \& Gras, 2014b), indicating a reduced ability to recover the original structure after shear-induced structural breakdown compared to bovine yoghurt (Folkenberg, Dejmek, Skriver, Guldager, \& Ipsen, 2006). The structure of buffalo yoghurt likely contributes to these properties, as the network is more porous and contains larger more numerous fat globules due to the high concentration of fat in buffalo milk (Nguyen et al., 2014b).

Lowering the fermentation temperature has been shown to reduce the syneresis of buffalo yoghurt, but only to a limited extent (Nguyen, Ong, Kentish, \& Gras, 2014a). Other strategies often employed in dairy processing to reduce syneresis are problematic; buffalo milk powders are not readily available and stabilisers or thickeners can be perceived as detracting from a natural product. Homogenisation may provide a simple unit operation to improve product 
properties but there is limited information on the application of homogenisation to buffalo milk. While a few studies report on selected properties of buffalo yoghurt made from homogenised milk (Ghadge, 2008; Raju \& Pal, 2009; Shiby \& Mishra, 2008), they do not provide comparisons between homogenised and unhomogenised products and there is no systematic study of the potential application of homogenisation and the optimisation of this process. The homogenisation of bovine milk has been extensively studied but the significant differences between buffalo milk and bovine milk such as fat content $(7.3 \pm 1.0 \% \mathrm{w} / \mathrm{w}$ vs. $4.1 \pm 0.4 \% \mathrm{w} / \mathrm{w})$ and fat globule size $(5.0 \pm 0.1 \mu \mathrm{m}$ vs. $3.5 \pm 0.2 \mu \mathrm{m})$ (Ménard et al., 2010) could lead to different yoghurt properties in response to homogenisation. As a result, the conditions for optimal processing may differ for two types of milk.

In this study, we investigate the potential use of homogenisation of buffalo milk at either 80 bar or 160 bar to reduce the syneresis and improve the rheological properties of buffalo yoghurt. The effect of homogenisation on the microstructure of buffalo yoghurt is also examined. Changes in the viscoelastic properties of the buffalo milk gel and the growth and viability of probiotic bacteria during fermentation and cold storage are investigated to better understand how homogenisation may be applied to buffalo yoghurt production.

\section{Materials and methods}

\subsection{Yoghurt preparation}

Raw buffalo milk was provided by a local dairy farm (Shaw River, Yambuk, Australia). Upon receipt, buffalo milk was divided into three portions (4 L per portion). One portion was used to produce an unhomogenised yoghurt sample and the other two portions of buffalo milk were warmed to $60{ }^{\circ} \mathrm{C}$ before homogenisation at 80 bar or 160 bar using a single stage homogeniser (GEA Panda Plus 1000, GEA Niro Soavi, Parma, Italy). Both the homogenised and unhomogenised milk portions were then batch-pasteurised at $85{ }^{\circ} \mathrm{C}$ for $30 \mathrm{~min}$ using a water bath (Qualtex, Watson Victor Ltd., Perth, Australia) and cooled to $40{ }^{\circ} \mathrm{C}$ for yoghurt production following a procedure described previously (Nguyen et al., 2014b). Briefly, the milk was inoculated with $0.062 \mathrm{~g} \mathrm{~L}^{-1}$ freeze dried direct vat starter culture ABT-5 containing probiotic Lactobacillus acidophilus La-5, Bifidobacterium lactis Bb-12 and Streptococcus thermophilus (CHR-Hansen, Bayswater, Australia), distributed into plastic containers of either $50 \mathrm{~mL}$ or 100 $\mathrm{mL}$ in volume and incubated at $40{ }^{\circ} \mathrm{C}$. Samples in containers $100 \mathrm{~mL}$ in volume were used for textural and rheological analyses, while samples in containers $50 \mathrm{~mL}$ in volume were used for 


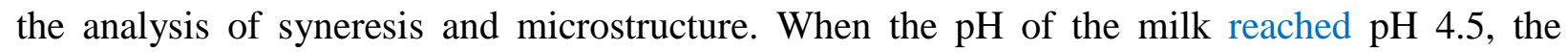
yoghurt samples were immediately transferred to a cold room $\left(4^{\circ} \mathrm{C}\right)$ and stored for $28 \mathrm{~d}$. The yoghurt making was replicated in a second trial on a different day for all treatments using the fresh milk sample collected on a different day with an average composition of $3.8 \pm 0.2 \%(\mathrm{w} / \mathrm{w}$ ) protein, $7.2 \pm 0.3 \%(\mathrm{w} / \mathrm{w})$ fat, $4.9 \pm 0.1 \%(\mathrm{w} / \mathrm{w})$ lactose and $16.7 \pm 0.2 \%(\mathrm{w} / \mathrm{w})$ total solids, determined using the methods presented in section 2.2.

\subsection{Measurement of $\mathrm{pH}$ and determination of fat, protein, lactose and total solids content}

Milk fat, protein content and $\mathrm{pH}$ were determined using methods described previously (Atwood \& Hartmann, 1992; Pesce \& Strande, 1973) using a spectrophotometer (Fluostar Optima, BMG labtech, Ortenberg, Germany) and a pH meter (Orion 720A plus, Orion Pacific Pty Ltd., Wallsend, Australia). The concentration of lactose in milk was determined following the method of Gosling et al. (2009) using an High Performance Liquid Chromatography Shimadzu Prominence system (Rydalmere, Australia) featuring a RID-10A refractive index detector and a Rezex RCM-Monosaccharide $\mathrm{Ca}^{2+}$ column measuring 300 x 7.8 mm (Phenomenex, Lane Cove, Australia). Total milk solids content was determined using an oven drying method (ISO/IDF, 2010). Three replicate samples were analysed for each treatment and two trials were conducted; the data presented are therefore the mean of six replicates.

\subsection{Measurement of size distribution of fat globules}

The size distribution of the milk fat globules in buffalo milk was determined by light scattering using a Mastersizer 2000 (Malvern Instruments, Malvern, UK) (Ong et al., 2010). The refractive index of the milk fat and distilled water was set at 1.460 and 1.330 , respectively. The milk sample was diluted (1:1 (v:v)) in ethylenediamine tetraacetic acid (EDTA; $50 \mathrm{mM}, \mathrm{pH}$ 7) (Merck, Kilsyth, Australia) for $2 \mathrm{~h}$ to dissociate the casein micelles. The mixture was then added gradually into the circulating cell of the apparatus containing distilled water and $0.05 \%(\mathrm{w} / \mathrm{v})$ sodium dodecyl sulphate (SDS; Merck) to dissociate the fat globule aggregates. Three measurements were performed for each treatment in each trial and two trials of yoghurt production were carried out; the results presented are therefore the mean of six measurements.

\subsection{Syneresis determination}

Syneresis was determined by centrifugation $\left(700 \mathrm{~g}, 8{ }^{\circ} \mathrm{C}, 10 \mathrm{~min}\right)$ as previously described by Purwandari, Shah, and Vasiljevic (2007) using a bench-top centrifuge (Eppendorf 5810R, North 
119 Ryde, Australia). The syneresis was expressed as a percentage of the weight of the expelled 120 whey over the initial weight of a yoghurt sample. Three replicate samples for each treatment in each trial were analysed at each time point during storage and two trials of yoghurt production were carried out; the results presented are therefore the mean of six measurements.

\subsection{Texture analysis}

124 The gel firmness of yoghurt was analysed using a TA.XT-2 texture analyser (Stable 125 Microsystems, Godalming, UK) equipped with a $2 \mathrm{~kg}$ load cell and a $10 \mathrm{~mm}$ cylindrical probe as 126 described in Nguyen et al. (2014b). Briefly, the texture analyser was set at a contact area of 1

$127 \mathrm{~mm}^{2}$, a contact force of $5 \mathrm{~g}$, an instrument speed of $1 \mathrm{~mm} \mathrm{~s}^{-1}$ and a compression distance of 20 $\mathrm{mm}$. The maximum force during penetration was defined as the gel firmness. Three replicate samples for each treatment in each trial were analysed at each time point during storage and two trials of yoghurt production were carried out; the results presented are therefore the mean of six measurements.

\subsection{Rheological analysis}

133 Rheological properties during fermentation and storage were analysed following methods 134 described in Nguyen et al. (2014b). A controlled strain rheometer (Advanced Rheometrics 135 Expansion System, TA Instruments, New Castle, DE, USA), equipped with a 34 mm diameter 136 cup and a six blade vane $32 \mathrm{~mm}$ in diameter and $33 \mathrm{~mm}$ in height, was used for the analysis of 137 rheological properties of samples during fermentation. Briefly, the equipment was set at an oscillation frequency of $0.1 \mathrm{~Hz}$, a constant strain of $1 \%$ and a temperature of $40{ }^{\circ} \mathrm{C}$. The storage modulus $\left(\mathrm{G}^{\prime}\right)$ and loss tangent $(\tan \delta)$ were measured every 5 min until the milk reached a $\mathrm{pH}$ of 4.5. Measurement was performed once for each treatment in each trial and two trials of yoghurt production were carried out; the results presented are therefore the mean of two measurements.

142 A controlled stress rheometer (AR-G2, TA Instruments Ltd.) fitted with a cone plate (40 mm 143 diameter $/ 4^{\circ}$ angle) was used to monitor rheological properties during storage. Briefly, the 144 measurement included an initial equilibration to $20^{\circ} \mathrm{C}$, a pre-shear at $500 \mathrm{~s}^{-1}$ for $60 \mathrm{~s}$, an 145 equilibration for $300 \mathrm{~s}$, a logarithmic increase in shear rate from 0.1 to $100 \mathrm{~s}^{-1}$ in $300 \mathrm{~s}$, a holding 146 time of $5 \mathrm{~s}$ at $100 \mathrm{~s}^{-1}$ and a logarithmic decrease in shear rate from 100 to $0.1 \mathrm{~s}^{-1}$ in $300 \mathrm{~s}$. The 147 hysteresis area, flow behaviour index and consistency coefficient were obtained by fitting the 148 data to the modified power law model $\left(\eta=\mathrm{K} \gamma^{\mathrm{n}-1}\right)$ where $\eta$ is the apparent viscosity (Pa s), $\gamma$ the 149 shear rate $\left(\mathrm{s}^{-1}\right), \mathrm{K}$ the consistency coefficient $\left(\mathrm{Pa} \mathrm{s}^{\mathrm{n}}\right)$ and $\mathrm{n}$ the flow behaviour index $\left(\mathrm{R}^{2}>0.97\right)$ 
using a method described previously (Purwandari \& Vasiljevic, 2009). The data were also fitted to the Herschel-Bulkley model $\left(\tau=\tau_{\mathrm{o}}+\mathrm{K} \gamma^{\mathrm{n}}\right)$ where $\tau$ is the shear stress $(\mathrm{Pa}), \tau_{\mathrm{o}}$ the yield stress $(\mathrm{Pa}), \mathrm{K}$ the consistency coefficient $\left(\mathrm{Pa} \mathrm{s}^{\mathrm{n}}\right)$ and $\mathrm{n}$ the flow behaviour index, as previously described by Ciron, Gee, Kelly, and Auty (2012) for the assessment of the yield stress values and a further comparison of the results obtained using different rheological models. The data were analysed using the Rheology Advantage Data Analysis software (Version V5.70, TA Instruments Ltd.). Three independent samples for each treatment in each trial were analysed at each time point during storage and two trials of yoghurt production were carried out; these results presented are therefore the mean of six measurements.

\subsection{Microstructural analysis using confocal laser scanning microscopy and cryo}

\section{0 scanning electron microscopy}

161 The CLSM analysis was carried out using an inverted confocal laser scanning microscope 162 (Leica TCS SP2; Leica Microsystems, Mannheim, Germany) as described in details in our previous work (Nguyen et al., 2014b). For CLSM observation, yoghurt and milk samples were stained with Nile Red and Fast Green FCF (both supplied by Sigma-Aldrich, St. Louis, MO, USA) for $30 \mathrm{~min}$. CLSM observation was carried out in a dark room and the excitation/ emission wavelength of Nile Red and Fast Green FCF were set at $488 \mathrm{~nm} / 500-600 \mathrm{~nm}$ and 633 $\mathrm{nm} / 650-710 \mathrm{~nm}$ respectively. For the milk analysis, the three dimensional (3D) images were reconstructed from a series of two dimensional (2D) layers (38-63 stacks of 2D images in each $3 \mathrm{D}$ image) and the total number of fat globules in a $1 \mu \mathrm{m}^{3}$ sample volume was analysed using image analysis software (Imaris, Bitplane, South Windsor, CT, USA) as previously described by Ong, Dagastine, Kentish, and Gras (2012). The results were presented as the total number of fat globules per $1 \mu \mathrm{L}$ of milk (conversion factor of $1 \mu \mathrm{m}^{3}=10^{-9} \mu \mathrm{L}$ ). Three 3D images were obtained for each milk treatment (in an additional trial) for the image analysis and the results presented are the mean of three analyses. For the yoghurt analysis, the cryo-SEM analysis was

175 performed using a field emission scanning electron microscope (Quanta, Fei Company, 176 Hillsboro, OR, USA.), as previously described by Ong et al. (2011). At least two CLSM and cryo SEM images were taken for each yoghurt treatment in each trial. Two trials of yoghurt were carried out and hence a minimum of four images were collected for each treatment. A typical image is presented in each of the figures. 


\subsection{Microbiological analysis}

181 The enumeration of bacteria during fermentation and storage were performed as previously described (Nguyen et al., 2014b). Two plates were selected for manual counting for each treatment in each trial and two trials of yoghurt were carried out; the results presented are therefore the mean of four counts.

\subsection{Statistical analysis}

187 Minitab software (V16, Minitab Inc., State College, PA, USA) was used for data analysis. The difference between means was assessed by one way analysis of variance (ANOVA) and Fisher's paired comparison using a significance level of $\mathrm{P}=0.05$.

\section{Results and discussion}

191 A single stage homogenisation process was selected to assess the effect of homogenisation on

192 buffalo milk, reflecting the process most commonly applied in the production of bovine yoghurt

193 (Ozer, 2010; Tamime \& Robinson, 2007; Varnam \& Sutherland, 1994). Two homogenisation 194 pressures of 80 bar or 160 bar were also selected, based on the pressures reported in previous 195 studies for buffalo yoghurt (74.5 bar (Shiby \& Mishra, 2008)) and the typical pressures applied 196 for milk homogenisation in bovine yoghurt production (100-200 bar (Lucey \& Singh, 1997)).

197 Our hypothesis was that both treatments would improve the quality of buffalo yoghurt, including 198 the microstructure and level of syneresis and that homogenisation at higher pressures would be 199 more effective.

\subsection{The effect of homogenisation on the size distribution, surface area and microstructure} of buffalo milk fat globules

202 Homogenisation at 80 bar or 160 bar resulted in a significant decrease in the size of fat globules

203 in buffalo milk and a considerable increase in specific surface area $(\mathrm{P}<0.05)$ (Table 1$)$. The 204 average volume-weighted mean diameter D[4,3] of fat globules in the milk sample homogenised 205 at 80 bar was reduced more than threefold, while the specific surface area of fat globules in this 206 sample increased by a factor of eight compared to the unhomogenised milk. Increasing the 207 homogenisation pressure from 80 bar to 160 bar led to a further decrease in $\mathrm{D}[4,3]$ of the fat 
globules from $1.6 \mu \mathrm{m}$ to $1.0 \mu \mathrm{m}$ and an increase in the specific surface area from $14 \mathrm{~m}^{2} \mathrm{~g}^{-1}$ fat to $20 \mathrm{~m}^{2} \mathrm{~g}^{-1}$ fat.

The size distribution of the fat globules was bimodal in all cases (Figure 1). In the unhomogenised samples, the major peak was at $5.8 \mu \mathrm{m}$ with a minor peak at $1.0 \mu \mathrm{m}$, corresponding to $93 \%$ and $7 \%$ of the total volume of fat respectively. For milk homogenised at $80 \mathrm{bar}$, the main peak shifted to $2.2 \mu \mathrm{m}$ (corresponding to $77 \% \mathrm{v} / \mathrm{v}$ ) and the minor peak to 0.2 $\mu \mathrm{m}$ (corresponding to $23 \% \mathrm{v} / \mathrm{v}$ ). An increase in homogenisation pressure to 160 bar resulted in a further shift of the main peak diameter to $1.5 \mu \mathrm{m}$ (corresponding to $55 \% \mathrm{v} / \mathrm{v}$ ) and an increase in the volume contribution of the minor peak to $45 \% \mathrm{v} / \mathrm{v}$ at $0.2 \mu \mathrm{m}$. The size distributions at both pressures were also less expansive and varied within the range of $0.04 \mu \mathrm{m}$ and $7.6 \mu \mathrm{m}$, while the distribution in the unhomogenised samples spanned from $0.6 \mu \mathrm{m}$ to $17.4 \mu \mathrm{m}$.

CLSM images confirmed the significant change in fat globule size observed by light scattering and show the appearance of a protein coating and some aggregation of fat (Figure 2). Fat globules were significantly smaller and more numerous in homogenised samples compared to unhomogenised milk (Figures $2 \mathrm{c}$ and e vs. $2 \mathrm{a}$ ) and were approximately $1-2 \mu \mathrm{m}$ in diameter (in the homogenised samples) compared to $\sim 5 \mu \mathrm{m}$ diameter (in the control). Smaller fat globules could also be observed in all samples, consistent with the bimodal distribution observed using light scattering (Figure 1). Aggregates or clusters of fat globules were larger and more numerous in samples homogenised at 160 bar than at 80 bar (Figures $2 \mathrm{e}$ and $\mathrm{f}$ vs. Figures $2 \mathrm{c}$ and d).

The behaviour of buffalo fat globules during homogenisation is consistent with the behaviour seen for bovine milk (Michalski, 2007; Walstra, Geurts, Noomen, Jellema, \& Boekel, 1999), where the combined effects of turbulence and cavitation are known to reduce fat globule size. Homogenisation induced damage to the milk fat globule membrane is also known to result in milk proteins absorbed to the fat globule surface (Cano-Ruiz \& Richter, 1997; Michalski et al., 2002; Ong et al., 2010). These proteins include mainly caseins and some denatured whey proteins (Michalski et al., 2002).

234 The efficiency of homogenisation, defined as the decrease in fat globule size, appears less for buffalo milk fat globules examined here compared to bovine milk fat globules, as similar pressures were reported by Walstra (1975) to reduce bovine fat globules to smaller diameters of $0.9 \mu \mathrm{m}(50 \mathrm{bar})$ and $0.5 \mu \mathrm{m}$ (150 bar) using a single stage homogeniser. When expressed as a 
percentage reduction in size, however, the changes induced in the larger buffalo fat globules are larger and the process more effective.

240 The clusters of coalesced fat globules or "homogenisation clusters" observed in both 241 homogenised buffalo milk samples are thought to occur due to the instability of the 242 homogenised fat globules (Ogden, Walstra, \& Morris, 1976; Walstra, 1975). Our observations 243 are similar to the findings of Doan (1929), who investigated the cluster formation of samples 244 with different fat concentrations ranging from $4.2 \%$ to $16.1 \%$ by mixing cream with fresh 245 bovine milk followed by a single stage homogenisation at 240 bar. Samples containing 7.2\% 246 bovine milk fat, similar to the fat content of buffalo milk, contained homogenisation clusters 247 while samples containing $4.2 \%$ bovine milk fat contained a well dispersed emulsion with little 248 clumping of fat. The larger specific surface area of the buffalo fat globules homogenised at 160 249 bar here (Table 1) may lead to a greater number of fat clusters (Figure 2f vs. Figure 2d).

250 Two stage homogenisation is thought to prevent the formation of homogenisation clusters 251 (Walstra et al., 1999). Such clusters can be prevented if the fat content of milk or cream samples 252 is less than $9 \%$ and a two stage homogeniser is used (Walstra et al., 1983). The two stage 253 process is not commonly used in the manufacture of bovine yoghurt (Ozer, 2010; Tamime \& 254 Robinson, 2007; Varnam \& Sutherland, 1994) but this process could have potential use for high 255 fat products, such as buffalo yoghurt. Our results also support the idea of lower homogenisation 256 pressures inducing fewer homogenisation clusters in buffalo milk. Indeed, two stage 257 homogenisation has been successfully applied to buffalo yoghurt production (Raju \& Pal, 2009) 258 but the effect on the microstructure of the milk has not been reported.

\subsection{The effect of homogenisation on the changes in pH, storage modulus and loss tangent} 260 during fermentation of buffalo yoghurt

261 The fermentation time, defined as the time for milk to reach $\mathrm{pH} 4.5$, was slightly shorter $(\sim 15$ $262 \mathrm{~min}$ ) in homogenised buffalo milk samples (Figure 3a). This may be due to the better 263 availability of nutrients released from the disrupted MFGM in homogenised samples, which can 264 promote the activity and metabolism of lactic acid bacteria.

265 Homogenisation led to a significant increase in storage modulus of buffalo yoghurt at the end of fermentation $(\mathrm{P}<0.05)$ (Figure $3 b)$. This result is consistent with previous studies for both acid 
and rennet gels made from homogenised bovine milk, where an increase in storage modulus was observed (Michalski et al., 2002; Sohrabvandi, Nematollahi, Mortazavian, \& Vafaee, 2013).

269

270

The increase in storage modulus is likely due to changes in the size and specific surface area of the fat globules and the composition of the milk fat globule membrane. In the unhomogenised buffalo samples, the fat globules are covered by the native MFGM, which acts as inactive material that interacts less with milk proteins. These fat globules fill the pores as inert fillers if the size is smaller than the serum pores or they act as structural breakers if the size is bigger than the serum pores (Michalski et al., 2002; Nguyen et al., 2014b), leading to a weaker protein network with a lower storage modulus. In contrast, the protein coating on the surface of the homogenised buffalo fat globules plays an active role as a structure promoter and takes part in the network formation during fermentation, as has been observed for bovine milk acid gels (Xiong \& Kinsella, 1991). This leads to a more cross-linked gel network resulting in an increased storage modulus in homogenised samples. Previous reports for bovine milk suggest that at least $40 \%$ of the surface area of the native membrane must be damaged and replaced by proteins in order for the storage modulus to be significantly altered (Michalski et al., 2002). The data presented here suggest buffalo milk fat globules behave in a similar way.

Some differences were observed in the response of buffalo milk fat globules to different homogenisation pressures compared to previous reports for bovine milk. Here the storage modulus at the end of the fermentation increased by more than $80 \%$ for yoghurt homogenised at 80 bar compared to the control sample. While the storage modulus of buffalo yoghurt produced from milk homogenised at 160 bar was higher than the control sample, it was lower than the yoghurt produced from milk homogenised at 80 bar at the end of fermentation. The lower storage modulus for buffalo yoghurt made from milk homogenised at an increased pressure is different to reports for acid and rennet gels made from bovine milk (Michalski et al., 2002). The difference in these responses is likely linked to the differences in the properties of buffalo milk including the higher fat content and bigger fat globules.

Homogenisation of buffalo milk also led to a more stable yoghurt network that was less easily deformed. The $\tan \delta$, which represents the ratio of the storage modulus $\left(\mathrm{G}^{\prime}\right)$ to the loss modulus $\left(\mathrm{G}^{\prime \prime}\right)$, was lower for homogenised samples (Figure 3c) but there was no significant difference (P $>0.05)$ between samples treated with the two homogenisation pressures.

\subsection{The effect of homogenisation on the syneresis of buffalo yoghurt}


Homogenisation significantly reduced the level of syneresis observed for buffalo yoghurt ( $\mathrm{P}<$ $0.05) \sim 6$ fold, from $12-14 \%(w / w)$ to $0.8-2.1 \%(w / w)$ (Figure $4 a)$. No significant difference was found in the syneresis of yoghurt samples treated at different homogenisation pressures (P > 0.05). Homogenisation at 80 bar is therefore sufficient to reduce whey separation in buffalo 302 yoghurt production.

303 The decrease in syneresis is possibly due to the reduction in the size of fat globules and

304

305

306 production of an interactive protein coating. This leads to the formation of a gel network with a greater number of cross-links within homogenised samples. The protein absorbed to the surface of homogenised milk fat globules can also immobilize water (Keogh \& O'Kennedy, 1998), an effect that could lead to a more hydrated product with less whey separation.

The results presented here indicate that homogenisation could be used in buffalo yoghurt production to reduce whey separation, minimizing the need to fortify buffalo milk with milk powder, stabilizer or emulsifiers. The level of syneresis observed is similar to that obtained for bovine yoghurt fortified with milk powder in our previous work (1-2\% w/w, Nguyen et al. (2014b)) but is lower than that observed for homogenised buffalo yoghurt in previous studies (20-31\% w/w) (Ghadge, 2008; Raju \& Pal, 2009), probably due to the differences in the method for syneresis determination, the processing conditions and the raw materials used for yoghurt production. Interestingly, syneresis has also been reduced in sheep yoghurt by milk homogenisation. These findings suggest homogenisation could be applied to a wide range of animal milk types for effective yoghurt production.

\subsection{The effect of homogenisation on the gel firmness of buffalo yoghurt}

Homogenisation significantly $(\mathrm{P}<0.05)$ increased yoghurt gel firmness (Figure $4 \mathrm{~b})$ by approximately 50\%, consistent with previous studies using bovine milk (Lucey, 2004), goat milk (Abrahamsen \& Holmen, 1981) and sheep milk (Muir \& Tamime, 1993). Interestingly, the gel firmness of buffalo yoghurt produced from homogenised milk at both pressures in this study was significantly higher than the gel firmness obtained for fortified and homogenised bovine yoghurt in our previous work (Nguyen et al., 2014b); despite the similar total solids content of the two milk preparations $(16.7 \pm 0.2$ vs. $16.8 \pm 0.1 \% \mathrm{w} / \mathrm{w})$ and the slightly lower protein concentration of the buffalo milk $(3.8 \pm 0.2$ vs. $4.6 \pm 0.3 \% \mathrm{w} / \mathrm{w})$, suggesting that the fat content or strength of the protein network are the contributing factors. 
Our results highlight the different properties of buffalo and bovine yoghurt following milk homogenisation. The gel firmness of yoghurt produced from buffalo milk homogenised at 160 bar was lower than for samples homogenised at 80 bar $(\mathrm{P}<0.05)$ (Figure $4 \mathrm{~b})$, consistent with the lower storage modulus for these samples (Figure 3b). This is different to results reported for bovine yoghurt (Michalski et al., 2002), where an increase in gel firmness was obtained with an increase in homogenisation pressure. These differences likely arise from the different composition, as discussed above. Interestingly, when bovine milk-based dessert products with a high fat content similar to buffalo yoghurt were studied ( $6.5 \%$ fat vs. $7.2 \pm 0.3 \%$ fat), a low homogenisation pressure of 50 bar increased the gel firmness while a further increase in the homogenisation pressure to 150 bar decreased the gel firmness (Sohrabvandi et al., 2013). These data indicate the importance of the fat content in determining the product properties.

Cold storage significantly $(\mathrm{P}<0.05)$ increased the gel firmness of yoghurt samples in all treatments and an increase of $0.32-0.38 \mathrm{~N}$ was observed over $28 \mathrm{~d}$ for homogenised samples, compared to an increase of only $0.18 \mathrm{~N}$ for the unhomogenised samples. An increase in gel firmness during cold storage was also observed in previous studies for buffalo, bovine and sheep yoghurt (Domagala, 2009; Nguyen et al., 2014b; Salvador \& Fiszman, 2004) but not in goat yoghurt (Domagala, 2009).

The increase observed for buffalo and other yoghurts may be due to the further development of the gel network or the production of exopolysaccharide (EPS) by the starter culture bacteria. EPS producing starter cultures can improve textural properties (Duboc \& Mollet, 2001; Folkenberg et al., 2006) and EPS concentration has been found to increase during cold storage of yoghurt in a previous study (Amatayakul, Halmos, Sherkat, \& Shah, 2006). Bifidobacterium lactis used here has previously been reported to produce EPS such as L-rhamnopyranose, Dglucopyranose, D-galactosepyranose and D-galactofuranose (Hidalgo-Cantabrana et al., 2013; Leivers et al., 2011), which could interact with the protein network leading to the observed increase in gel firmness. The properties of buffalo yoghurt are likely to differ to goat yoghurt, as goat milk contains a lower concentration of casein and higher concentration of non-protein nitrogen (Domagala, 2009; Park, Juárez, Ramos, \& Haenlein, 2007).

The firmness of yoghurt also depends on the $\mathrm{pH}$ (Walstra et al., 1999). Yoghurt generally has a higher gel firmness at a lower $\mathrm{pH}$, with a preferred $\mathrm{pH}$ range of 4.1 and 4.6 (Walstra et al., 1999). A further drop in $\mathrm{pH}$ can occur during the cold storage following fermentation, often 
referred to as post acidification; $\mathrm{pH}$ was not monitored during storage in this study but could contribute to the increase in gel firmness observed here and would be worthy of further study.

\subsection{The effect of homogenisation on the rheological properties of buffalo yoghurt}

Homogenisation appears effective at improving the texture and rheological properties of buffalo yoghurt, as indicated by the significant decrease in the hysteresis area and consistency coefficient and significant increase in the flow behaviour index $(\mathrm{P}<0.05)$ (Figure 5). An increase in homogenisation from 80 bar to 160 bar, however, did not have a significant effect ( $\mathrm{P}$ $>0.05$ ) on each of these rheological properties.

The rheological flow curves that measure shear induced structural deformation differed between control and homogenised yoghurt samples (see supplementary Figure A.1 for an example flow curve). A plot of the stress scaled hysteresis area as a function of the shear stress at the maximum shear rate $\left(\tau_{100}\right)$ obtained from these curves provides further insights into the shear induced structural degradation in these samples (Figure 5a). The shear stress at the maximum shear rate increased following homogenisation, with the exception of data collected for the 80 bar sample after $28 \mathrm{~d}$ of storage. The stress scaled hysteresis area (Figure 5 a) and the total hysteresis area (Figure 5 b) were significantly reduced following homogenisation, indicating increased stability (Jaros, Heidig, \& Rohm, 2007) and an ability to recover the original structure after deformation (Folkenberg et al., 2006). These rheological properties are consistent with the improved texture of homogenised yoghurt samples, including the lower whey separation (Figure 4a) and the firmer gel (Figure 4b).

The consistency coefficient, defined as the apparent viscosity at shear rate of $1 \mathrm{~s}^{-1}$, was found to be between 10-25 Pa.s $\mathrm{s}^{\mathrm{n}}$ for samples assessed after one day of storage where the data was fitted with the modified power law model $\left(\mathrm{R}^{2} \sim 0.97-0.99\right)$ (Figure $5 \mathrm{c}$ ). The magnitude of these consistency coefficients is within the wide range reported for bovine yoghurt of 0.76-165.03 Pa $\mathrm{s}^{\mathrm{n}}$ (Abu-Jdayil \& Mohameed, 2002; Purwandari et al., 2007) and buffalo yoghurt of 4.9 - $35.2 \mathrm{~Pa}$ $\mathrm{s}^{\mathrm{n}}$ (Bezerra, Souza, \& Correia, 2012) where the power law or modified power law model has been applied.

Alternatively, a yield stress may be determined from the flow curves and the data fitted to the Herschel-Bulkley model. The yield stress, defined as the initial stress or force required to initiate the yoghurt to flow, was $20.7 \pm 11.5 \mathrm{~Pa}$ for the control yoghurts. This yield stress was 
significantly higher $(\mathrm{P}<0.05)$ than those obtained for the samples made from milk homogenised at 80 bar and 160 bar, which were $11.4 \pm 2.0 \mathrm{~Pa}$ or $10.6 \pm 1.9 \mathrm{~Pa}$, respectively (Supplementary Figure A.1).

The consistency coefficient determined from the Herschel-Bulkley model for samples assessed after one day of storage was smaller in magnitude (1-2.5 Pa.s $\left.{ }^{n}\right)$ but the trends observed were consistent with those determined using the modified power law model, despite a poorer fit to the data $\left(\mathrm{R}^{2} \sim 0.15-0.97\right)$. These values of consistency coefficient are also within the range of $0.1-$ 88.86 $\mathrm{Pa} \mathrm{s}^{\mathrm{n}}$, previously reported for bovine yoghurt using the Herschel-Bulkley model (Ciron et al., 2012; Paseephol, Small, \& Sherkat, 2008; Paskov, Karsheva, \& Pentchev, 2010).

The homogenised samples also exhibited a significantly higher flow behaviour index compared to the control samples (Figure 5d), indicating these samples are more Newtonian in behaviour. The range of flow behaviour index recorded is within the range of 0.08-0.56 previously reported for bovine yoghurt using the power law model (Abu-Jdayil \& Mohameed, 2002; Espírito-Santo et al., 2013). When the data are fitted to the Herschel-Bulkley model the trends are similar but magnitude of the numbers larger ( 0.56-0.89), consistent with the range reported of 0.26-0.83 using this model in the literature (Paseephol et al., 2008; Paskov et al., 2010).

The observations recorded here are in agreement with a previous study (Shaker, Abu Jdayil, \& Jumah, 2002), where a decrease in consistency coefficient and an increase in the flow behaviour index were observed for yoghurt made from homogenised bovine milk.

\subsection{The effect of homogenisation on the microstructure of buffalo yoghurt}

Cryo-SEM images of the microstructure of buffalo yoghurt show that the fat globules in the homogenised samples are smaller than in the unhomogenised samples (Figures 6c and e vs. 6a, Figures $6 \mathrm{~d}$ and $\mathrm{f}$ vs. 6b). Most of these small fat globules are integrated within the protein network, which makes them almost indistinguishable from this network (Figures 6c-f). There are also a few remaining fat globules with size of approximately 2-3 $\mu \mathrm{m}$ observed within the microstructure of the samples homogenised at 80 bar (Figures 6c-d).

The protein network produced from homogenised milk shows thicker protein strands compared to the unhomogenised samples, especially after $28 \mathrm{~d}$ of storage (Figures $6 \mathrm{~d}$ and $\mathrm{f} v \mathrm{vs}$. 6b). The thicker protein strands and the more interconnected gel networks observed in the microstructure 
418 of homogenised buffalo yoghurt are consistent with the firmer gel and higher stability of this 419 yoghurt.

420 The CLSM images of the yoghurt microstructure confirm the presence of the smaller fat 421 globules in the homogenised yoghurt samples (Figures 7c and e). The fat globules in the control 422 samples are large and located within the serum pores as inert fillers (Figures 7a-b). In contrast, 423 the fat globules in the homogenised samples are better embedded within the protein network 424 (Figures 7c-e and d-f). Clusters of fat globules could also be observed within the protein aggregates in the microstructure of the homogenised samples (indicated by arrows in Figure 7), similar to observations of the homogenised milk (Figures $2 \mathrm{~d}$ and $\mathrm{f}$ ). There was no obvious difference, however, between the microstructure of the yoghurt samples produced from buffalo milk homogenised at different pressures. This suggests that the bulk microstructure is not responsible for the differences observed in storage modulus and gel firmness, although the strength of binding between components in the microstructure may play a role.

\subsection{The effect of homogenisation on the growth and viability of bacteria of buffalo yoghurt}

Homogenisation had no significant effect on the growth of the bacteria during fermentation (Figure 8) $(\mathrm{P}>0.05)$ but led to a decrease in the viability of Lactobacillus acidophilus at the end of the storage period $(\mathrm{P}<0.05)$ (Figure 8a), particularly for milk homogenised at 80 bar. This is possibly due to the increased activity of the Streptococcus thermophilus that may result from the better availability of nutrients within homogenised samples. The greater production of metabolites by Streptococcus thermophiles may in turn adversely affect the viability of Lactobacillus acidophilus. This result indicates that homogenisation may have a negative effect on the viability of probiotic bacteria during the storage of buffalo yoghurt. An increase in the number of bacteria used for inoculation, the use of a different strain of probiotic bacteria or the use of encapsulation technology may improve bacterial survival during storage.

\section{Conclusion}

443 Homogenisation significantly affected the properties of buffalo milk fat globules and improved 444 the properties of buffalo yoghurt. Treatment at either 80 bar or 160 bar decreased the fat globule 445 size, increased the specific surface area of fat and led to a protein coating and formation of fat 446 clusters. These changes affected the properties of yoghurt improving the microstructure and 447 rheological properties; syneresis was reduced approximately five fold and the texture was 
improved, resulting in a firmer gel, a higher storage modulus with a lower hysteresis area that demonstrates a better capacity to recover upon deformation. The protein microstructure of buffalo yoghurt made from homogenised milk also appeared dense with small fat globules embedded within this network. Our results suggest that homogenisation in the range of 80-160 bar can be used to improve the quality of buffalo yoghurt, especially to decrease syneresis and large differences are not observed within this range of pressures. Homogenisation of buffalo milk avoids the need for strategies such as milk fortification or addition of stabilisers and offers a solution more effective than lowering the temperature during fermentation.

\section{Acknowledgements}

The authors would like to acknowledge the Australian Government for providing an Australian Postgraduate Award (International) (APA - International) scholarship, the Rural Industries Research and Development Cooperation (RIRDC) for financial support and Shaw River for supplying the buffalo milk used in this study. The authors also thank the Particulate Fluids Processing Centre (PFPC), the Electron Microscopy Unit and the Biological Optical Microscopy Platform of the Bio21 Molecular Science and Technology Institute for access to equipment, $\mathrm{Mr}$ Roger Curtain for his help in operating the cryo-SEM and Dr Sandy Clarke (Department of Mathematics and Statistics, University of Melbourne) for her assistance in statistical analysis. Dr Lydia Ong and Associate Professor Sally Gras are supported by The ARC Dairy Innovation Hub.

\section{References}

Abrahamsen, R. K., \& Holmen, T. B. (1981). Goat's milk yoghurt made from non-homogenised and homogenised milks, concentrated by different methods. Journal of Dairy Research, 48, 457-463.

Abu-Jdayil, B., \& Mohameed, H. (2002). Experimental and modelling studies of the flow properties of concentrated yoghurt as affected by the storage time. Journal of Food Engineering, 52, 359-365.

Amatayakul, T., Halmos, A. L., Sherkat, F., \& Shah, N. P. (2006). Physical characteristics of yoghurts made using exopolysaccharide-producing starter cultures and varying casein to whey protein ratios. International Dairy Journal, 16, 40-51.

Atwood, C. S., \& Hartmann, P. E. (1992). Collection of fore and hind milk from the sow and the changes in milk-composition during suckling. Journal of Dairy Research, 59, 287-298.

Bezerra, M. F., Souza, D. F. S., \& Correia, R. T. P. (2012). Acidification kinetics, physicochemical properties and sensory attributes of yoghurts prepared from mixtures of goat and buffalo milks. International Journal of Dairy Technology, 65, 437-443.

Cano-Ruiz, M. E., \& Richter, R. L. (1997). Effect of homogenisation pressure on the milk fat globule membrane proteins. Journal of Dairy Science, 80, 2732-2739. 
Chandan, R. C., \& O'Rell, K. R. (2006). Manufacturing yoghurt and fermented milks (1st edn. Chapt. 12). Oxford, UK: Wiley-Blackwell.

Ciron, C. I. E., Gee, V. L., Kelly, A. L., \& Auty, M. A. E. (2012). Modifying the microstructure of low-fat yoghurt by microfluidisation of milk at different pressures to enhance rheological and sensory properties. Food Chemistry, 130, 510-519.

Doan, F. J. (1929). Some factors affecting the fat clumping produced in milk and cream mixtures when homogenised. Journal of Dairy Science, 12, 211-230.

Domagala, J. (2009). Instrumental texture, syneresis and microstructure of yoghurts prepared from goat, cow and sheep milk. International Journal of Food Properties, 12, 605-615.

Duboc, P., \& Mollet, B. (2001). Applications of exopolysaccharides in the dairy industry. International Dairy Journal, 11, 759-768.

Espírito-Santo, A. P., Lagazzo, A., Sousa, A. L. O. P., Perego, P., Converti, A., \& Oliveira, M. N. (2013). Rheology, spontaneous whey separation, microstructure and sensorial characteristics of probiotic yoghurts enriched with passion fruit fiber. Food Research International, 50, 224-231.

Folkenberg, D. M., Dejmek, P., Skriver, A., Guldager, H. S., \& Ipsen, R. (2006). Sensory and rheological screening of exopolysaccharide producing strains of bacterial yoghurt cultures. International Dairy Journal, 16, 111-118.

Ghadge, P. N. (2008). Effect of fortification on the physico-chemical and sensory properties of buffalo milk yoghurt. Electronic Journal of Environmental, Agricultural and Food Chemistry, 7, 2890-2899.

Gosling, A., Alftren, J., Stevens, G. W., Barber, A. R., Kentish, S. E., \& Gras, S. L. (2009). Facile pretreatment of Bacilius circulans beta-galactosidase increases the yield of galactosyl oligosaccharides in milk and lactose reaction systems. Journal of Agricultural and Food Chemistry, 57, 11570-11574.

Hidalgo-Cantabrana, C., Sanchez, B., Moine, D., Berger, B., de Los Reyes-Gavilán, C. G., Sánchez, B., Gueimonde, M., Margolles, A., \& Ruas Madiedo, P. (2013). Insights into the ropy phenotype of the exopolysaccharide-producing strain Bifidobacterium animalis subsp. lactis A1dOxR. Applied and Environmental Microbiology, 79, 3870-3874.

ISO/IDF. (2010). Milk, cream and evaporated milk - Determination of total solids content. International standard ISO 6731-IDF 21. Brussels, Belgium: International Dairy Federation.

Jaros, D., Heidig, C., \& Rohm, H. (2007). Enzymatic modification through microbial transglutaminase enhances the viscosity of stirred yoghurt. Journal of Texture Studies, $38,179-198$.

Keogh, K. M., \& O’Kennedy, B. T. (1998). Rheology of stirred yoghurt as affected by added milk fat, protein and hydrocolloids. Journal of Food Science, 63, 108-112.

Lee, W. J., \& Lucey, J. A. (2003). Rheological properties, whey separation, and microstructure in set-style yoghurt: Effects of heating temperature and incubation temperature. Journal of Texture Studies, 34, 515-536.

Leivers, S., Hidalgo-Cantabrana, C., Robinson, G., Margolles, A., Ruas-Madiedo, P., \& Laws, A. P. (2011). Structure of the high molecular weight exopolysaccharide produced by Bifidobacterium animalis subsp lactis IPLA-R1 and sequence analysis of its putative eps cluster. Carbohydrate Research, 346, 2710-2717.

Lucey, J. A., \& Singh, H. (1997). Formation and physical properties of acid milk gels: a review. Food Research International, 30, 529-542.

Lucey, J. A. (2004). Cultured dairy products: an overview of their gelation and texture properties. International Journal of Dairy Technology, 57, 77-84.

Ménard, O., Ahmad, S., Rousseau, F., Briard-Bion, V., Gaucheron, F., \& Lopez, C. (2010). Buffalo vs. cow milk fat globules: Size distribution, zeta-potential, compositions in total 
fatty acids and in polar lipids from the milk fat globule membrane. Food Chemistry, 120, 544-551.

Michalski, M. C., Cariou, R., Michel, F., \& Garnier, C. (2002). Native vs. damaged milk fat globules: membrane properties affect the viscoelasticity of milk gels. Journal of Dairy Science, 85, 2451-2461.

Michalski, M. C. (2007). On the supposed influence of milk homogenisation on the risk of CVD, diabetes and allergy. British Journal of Nutrition, 97, 598-610.

Muir, D. D., \& Tamime, A. Y. (1993). Ovine milk. 3. Effect of seasonal-variations on properties of set and stirred yoghurts. Milchwissenschaft, 48, 509-513.

Nguyen, H. T. H., Ong, L., Kentish, S. E., \& Gras, S. L. (2014a). The effect of fermentation temperature on the microstructure, physicochemical and rheological properties of probiotic buffalo yoghurt. Food and Bioprocess Technology, 7, 2538-2548.

Nguyen, H. T. H., Ong, L., Lefevre, C., Kentish, S. E., \& Gras, S. L. (2014b). The miscrostructure and physicochemical properties of probiotic buffalo yoghurt during fermentation and storage: a comparison with bovine yoghurt. Food and Bioprocess Technology, 7, 937-953.

Ogden, L. V., Walstra, P., \& Morris, H. A. (1976). Homogenisation-induced clustering of fat globules in cream and model systems. Journal of Dairy Science, 59, 1727-1737.

Ong, L., Dagastine, R. R., Kentish, S. E., \& Gras, S. L. (2010). The effect of milk processing on the microstructure of the milk fat globule and rennet induced gel observed using confocal laser scanning microscopy. Journal of Food Science, 75, 135-145.

Ong, L., Dagastine, R. R., Kentish, S. E., \& Gras, S. L. (2011). Microstructure of milk gel and cheese curd observed using cryo scanning electron microscopy and confocal microscopy. Lwt-Food Science and Technology, 44, 1291-1302.

Ong, L., Dagastine, R. R., Kentish, S. E., \& Gras, S. L. (2012). The effect of pH at renneting on the microstructure, composition and texture of Cheddar cheese. Food Research International, 48, 119-130.

Ozer, B. (2010). Strategies for yoghurt manufacturing. In F. Yildiz (Ed.), Development and manufacture of yoghurt and other functional dairy products (pp. 47-96). Boca Raton, FL, USA: CRC Press, Taylor and Francis Group.

Park, Y. W., Juárez, M., Ramos, M., \& Haenlein, G. F. W. (2007). Physico-chemical characteristics of goat and sheep milk. Small Ruminant Research, 68, 88-113.

Paseephol, T., Small, D. M., \& Sherkat, F. (2008). Rheology and texture of set yoghurt as affected by inulin addition. Journal of Texture Studies, 39, 617-634.

Paskov, V., Karsheva, M., \& Pentchev, I. (2010). Effect of starter culture and homogenisation on the rheological properties of yoghurt. Journal of the University of Chemical Technology and Metallurgy, 45, 59-66.

Pesce, M. A., \& Strande, C. S. (1973). New micromethod for determination of protein in cerebrospinal-fluid and urine. Clinical Chemistry, 19, 1265-1267.

Purwandari, U., Shah, N. P., \& Vasiljevic, T. (2007). Effects of exopolysaccharide-producing strains of Streptococcus thermophilus on technological and rheological properties of settype yoghurt. International Dairy Journal, 17, 1344-1352.

Purwandari, U., \& Vasiljevic, T. (2009). Rheological properties of fermented milk produced by a single exopolysaccharide producing Streptococcus thermophilus strain in the presence of added calcium and sucrose. International Journal of Dairy Technology, 62, 411-421.

Raju, P., \& Pal, D. (2009). The physicochemical, sensory, and textural properties of misti dahi prepared from reduced fat buffalo milk. Food and Bioprocess Technology, 2, 101-108.

Rao, M. A., \& Lopes da Silva, J. A. (2007). Role of rheological behaviour in sensory assessment of foods and swallowing. In M. A. Rao (Ed.), Rheology of fluid and semisolid foods: 
Principles and applications (pp. 403-426). New York, NY, USA: Springer Science and Bussiness Media.

Salvador, A., \& Fiszman, S. M. (2004). Textural and sensory characteristics of whole and skimmed flavored set-type yoghurt during long storage. Journal of Dairy Science, 87, 4033-4041.

Sameen, A., Anjum, F. M., Huma, N., \& Nawaz, H. (2010). Chemical composition and sensory evaluation of Mozzarella cheese: influence by milk sources, fat levels, starter cultures and ripening period. Pakistan Journal of Agricultural Sciences, 47, 26-31.

Shaker, R. R., Abu Jdayil, B., \& Jumah, R. Y. (2002). Rheological properties of set yoghurt as influenced by incubation temperature and homogenisation. Journal of Food Quality, 25, 409-418.

Shiby, V. K., \& Mishra, H. N. (2008). Modelling of acidification kinetics and textural properties in dahi (Indian yoghurt) made from buffalo milk using response surface methodology. International Journal of Dairy Technology, 61, 284-289.

Sodini, I., Remeuf, F., Haddad, S., \& Corrieu, G. (2004). The relative effect of milk base, starter, and process on yoghurt texture: A review. Critical Reviews in Food Science and Nutrition, 44, 113-137.

Sohrabvandi, S., Nematollahi, A., Mortazavian, A. M., \& Vafaee, R. (2013). Effect of homogenisation pressure and sequence on textural and microstructural properties of milk based creamy dessert. Journal of Paramedical Sciences, 4, 1-7.

Tamime, A. Y., \& Robinson, R. K. (2007). Yoghurt: Science and Technology (3rd edn., Chapt. 2 and 5). Cambridge, UK: Woodhead Publishing.

Varnam, A. H., \& Sutherland, J. P. (1994). Milk and milk products:Technology, chemistry and microbiology (Chapt. 8). London, UK: Chapman and Hall.

Walstra, P. (1975). Effect of homogenisation on fat globule size distribution in milk. Netherlands Milk and Dairy Journal, 29, 279-294.

Walstra, P., Geurts, T. J., Noomen, A., Jellema, A., \& Boekel, M. A. J. S. (1999). Dairy technology: Principles of milk properties and processes (Chapt. 8 and 20). New York, NY, USA: Marcel Dekker.

Xiong, Y. L., \& Kinsella, J. E. (1991). Influence of fat globule-membrane composition and fat type on the rheological properties of milk based composite gels. 2. Results. Milchwissenschaft, 46, 207-212. 
619 Figure 1. Size distribution of fat globules in unhomogenised buffalo milk (control, •) and in 620 buffalo milk homogenised at 80 bar (•) or 160 bar (०) obtained using light scattering. Each data 621 point is the average of six measurements $(n=6)$ and the error bars are the standard deviation of 622 the mean.

623 Figure 2. Confocal laser scanning microscopy images of the microstructure of unhomogenised buffalo milk (control, a-b), buffalo milk homogenised at 80 bar (c-d) or 160 bar (e-f). The images were captured using a 100x objective at 2x digital zoom (the first row) or 4x digital zoom (the second row). The scale bars are $5 \mu \mathrm{m}$ in length. Arrows in Figures $2 \mathrm{~d}$ and $2 \mathrm{f}$ indicate fat clusters induced by homogenisation. Please refer to the online edition for a colour version of this figure.

Figure 3. Changes in $\mathrm{pH}$ (a), storage modulus $\left(\mathrm{G}^{\prime}\right)(\mathrm{b})$ and loss tangent (tan $\delta$ ) (c) during the

630 fermentation of buffalo yoghurt produced from unhomogenised milk (control, •), milk 631 homogenised at 80 bar (•) or milk homogenised at $160 \mathrm{bar}(0)$. Each data point is the average of six measurements $(n=6)$ in Figure $3 a$ and the average of two measurements $(n=2)$ in Figures $3 \mathrm{~b}$ and $\mathrm{c}$. The error bars are the standard deviation of the mean.

634 Figure 4. Changes in the syneresis (a) and gel firmness (b) of buffalo yoghurt produced from unhomogenised buffalo milk (control, •), buffalo milk homogenised at 80 bar (•) or 160 bar (०) 636 during cold storage. Each data point is the average of six replicates $(n=6)$. The error bars are the 637 standard deviation of the mean.

638 Figure 5. Changes in the stress-scaled hysteresis area (a), hysteresis area (b), consistency coefficient (c) and flow behaviour index (d) of buffalo yoghurt produced from unhomogenised

640 buffalo milk (control, •), buffalo milk homogenised at 80 bar (•) or 160 bar (o) during cold 641 storage. Each data point is the average of six replicates $(n=6)$ and the error bars are the standard 642 deviation of the mean.

643 Figure 6. Microstructure of buffalo yoghurt produced from unhomogenised buffalo milk 644 (control, a-b), buffalo milk homogenised at 80 bar (c-d) or 160 bar (e-f) at d 1 (upper images) 645 and d 28 (lower images) of storage as observed by cryo-scanning electron microscopy. Images 
646 were captured using a solid state detector at 16000x magnification. The scale bars are $5 \mu \mathrm{m}$ in 647 length.

648 Figure 7. Microstructure of buffalo yoghurt produced from unhomogenised buffalo milk 649 (control, a-b), buffalo milk homogenised at 80 bar (c-d) or 160 bar (e-f) at d 1 (upper images) 650 and d 28 (lower images) of storage, as observed by confocal laser scanning microscopy. Images 651 were captured using a $63 \mathrm{x}$ objective. The scale bars are $10 \mu \mathrm{m}$ in length. Arrows indicate the fat 652 cluster. Please refer to the online edition for a colour version of this figure.

653 Figure 8. Growth and viability of Lactobacillus acidophilus La-5 (a), Streptococcus 654 thermophilus (b) and Bifidobacterium lactis Bb-12 (c) during the fermentation and storage of 655 buffalo yoghurt produced from unhomogenised buffalo milk (control, •), buffalo milk 656 homogenised at 80 bar $(\bullet)$ or 160 bar (o). Each data point is the average of four replicates $(\mathrm{n}=4)$ 657 and the error bars are the standard deviation of the mean. 
Table 1. Specific surface area and volume-weighted mean diameter D[4,3] of fat globules in homogenised and control (unhomogenised) buffalo milk determined using light scattering. Data are the mean \pm the standard deviation of the mean $(n=6)$.

\begin{tabular}{lccc}
\hline \multicolumn{1}{c}{ Parameters } & Control & $\begin{array}{r}\text { Milk homogenised } \\
\text { at } 80 \text { bar }\end{array}$ & $\begin{array}{c}\text { Milk homogenised at } \\
160 \text { bar }\end{array}$ \\
\hline $\begin{array}{l}\text { Specific surface area }\left(\mathrm{m}^{2} \mathrm{~g}^{-1} \text { fat }\right) \\
\text { Diameter } \mathrm{D}[4,3](\mu \mathrm{m})\end{array}$ & $1.6 \pm 0.0^{\mathrm{c}}$ & $14 \pm 0.3^{\mathrm{b}}$ & $20 \pm 0.5^{\mathrm{a}}$ \\
& $5.3 \pm 0.1^{\mathrm{a}}$ & $1.6 \pm 0.0^{\mathrm{b}}$ & $1.0 \pm 0.1^{\mathrm{c}}$ \\
\hline
\end{tabular}

Significant differences $(\mathrm{P}<0.05)$ between homogenised and unhomogenised buffalo milk samples are indicated by different superscripts ${ }^{\text {abc }}$ in the same row. 


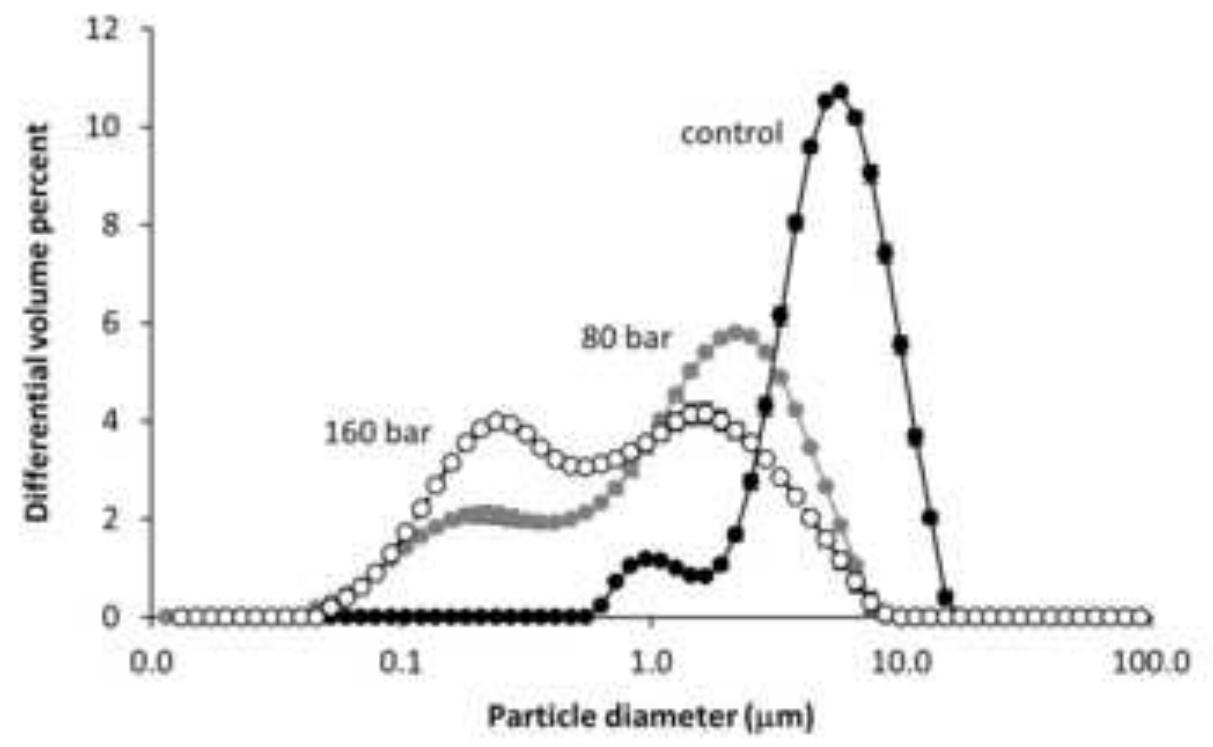

Figure 1. Size distribution of fat globules in unhomogenised buffalo milk (control, •) and in buffalo milk homogenised at 80 bar $(\bullet)$ or 160 bar $(\circ)$ obtained using light scattering. Each data point is the average of six measurements ( $\mathrm{n}=6)$ and the error bars are the standard deviation of the mean. 
Figure 2

Click here to download high resolution image
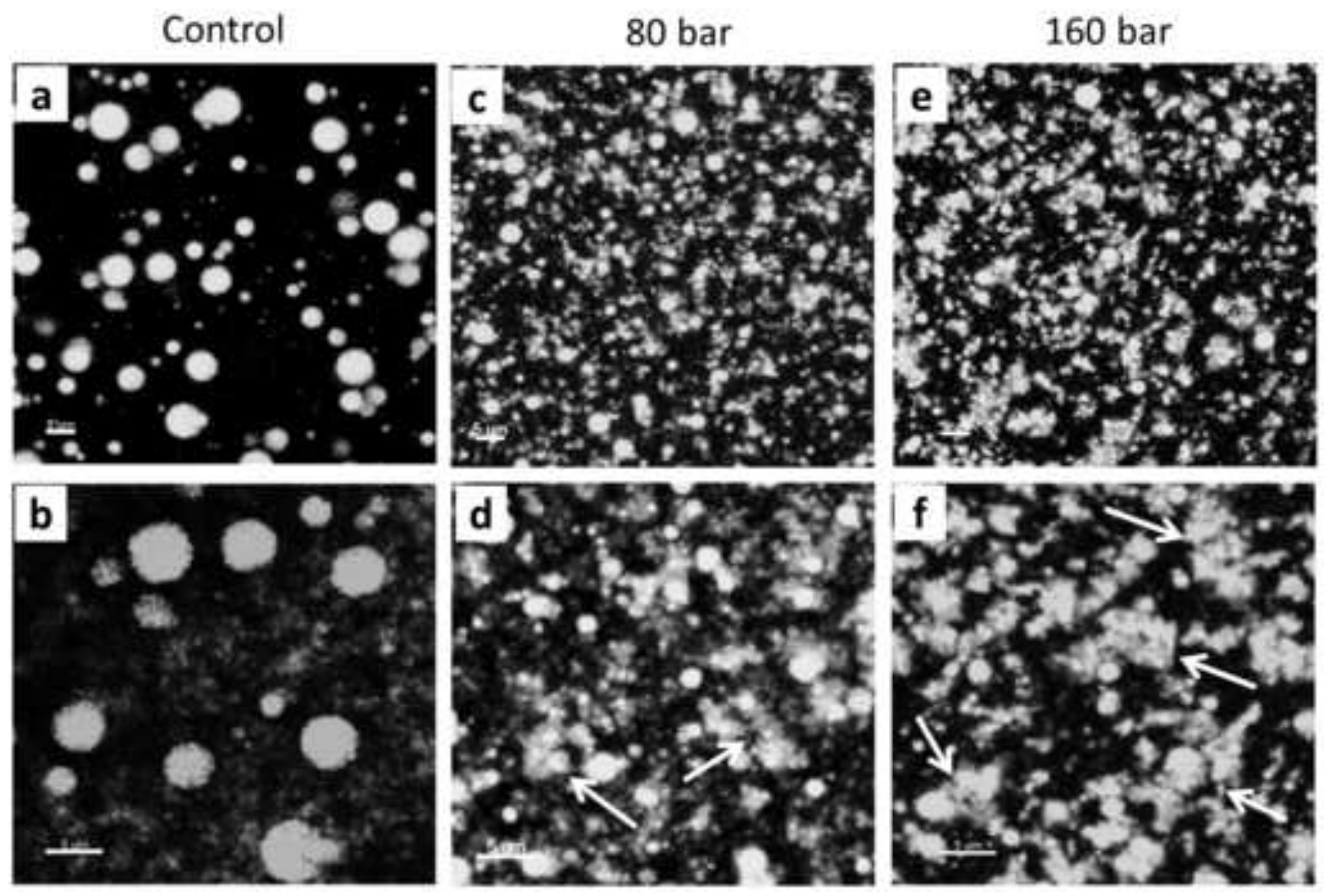

Figure 2. Confocal laser scanning microscopy images of the microstructure of unhomogenised buffalo milk (control, a-b), buffalo milk homogenised at 80 bar (c-d) or 160 bar (e-f). The images were captured using a 100x objective at $2 x$ digital zoom (the first row) or $4 \mathrm{x}$ digital zoom (the second row). The scale bars are $5 \mu \mathrm{m}$ in length. Arrows in Figures $2 \mathrm{~d}$ and $2 \mathrm{f}$ indicate fat clusters induced by homogenisation. Please refer to the online edition for a color version of this figure. 

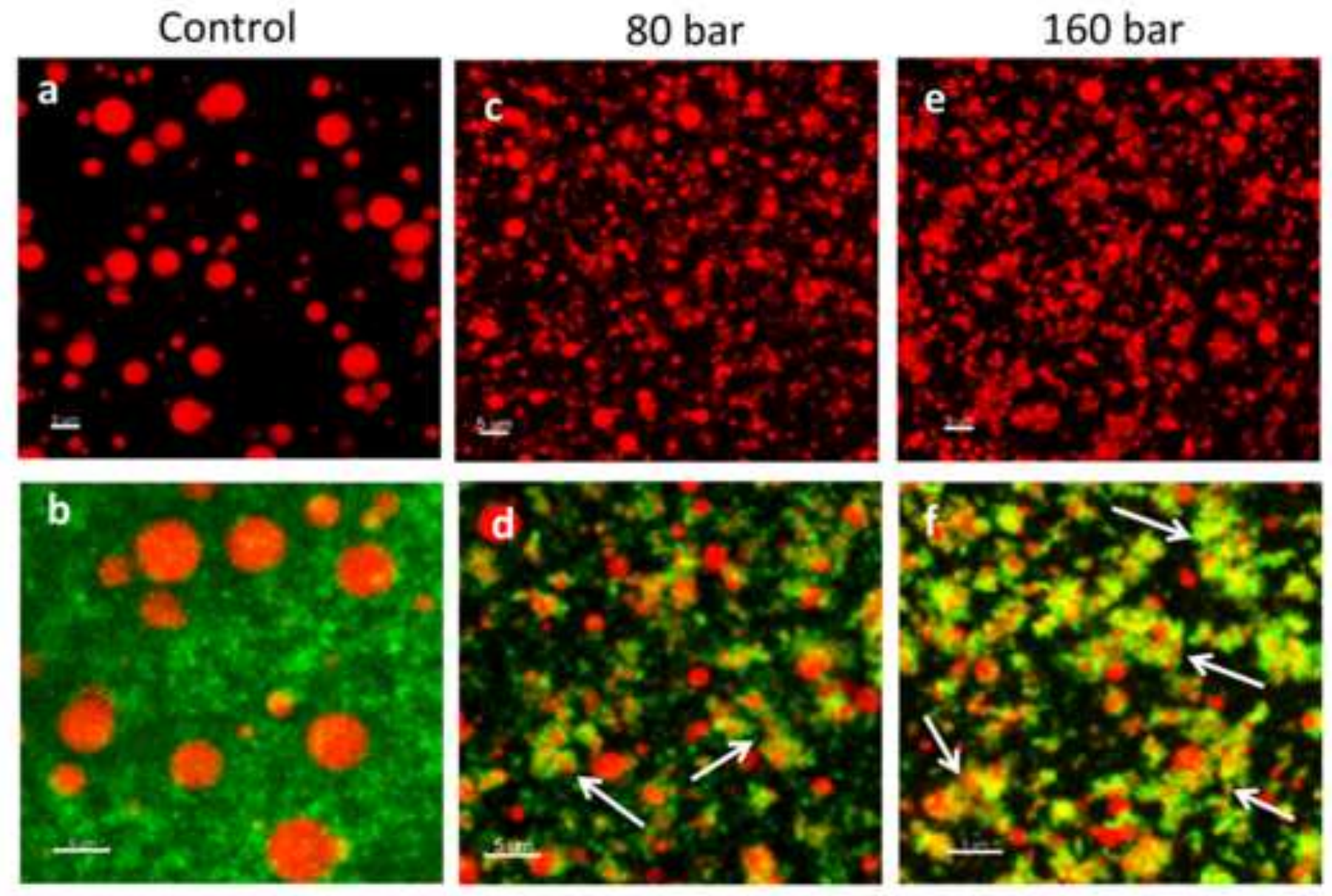

Figure 2 (online version). Confocal laser scanning microscopy images of the microstructure of unhomogenised buffalo milk (control, a-b), buffalo milk homogenised at 80 bar (c-d) or 160 bar (e-f). Nile Red stained fat appears red, FCF stained protein appears green. The images were captured using a 100x objective at $2 \mathrm{x}$ digital zoom (the first and second row) or $4 \mathrm{x}$ digital zoom (the third row). The scale bars are $5 \mu \mathrm{m}$ in length. Arrows in Figures $2 \mathrm{~d}$ and $2 \mathrm{f}$ indicate fat clusters induced by homogenisation. 
a

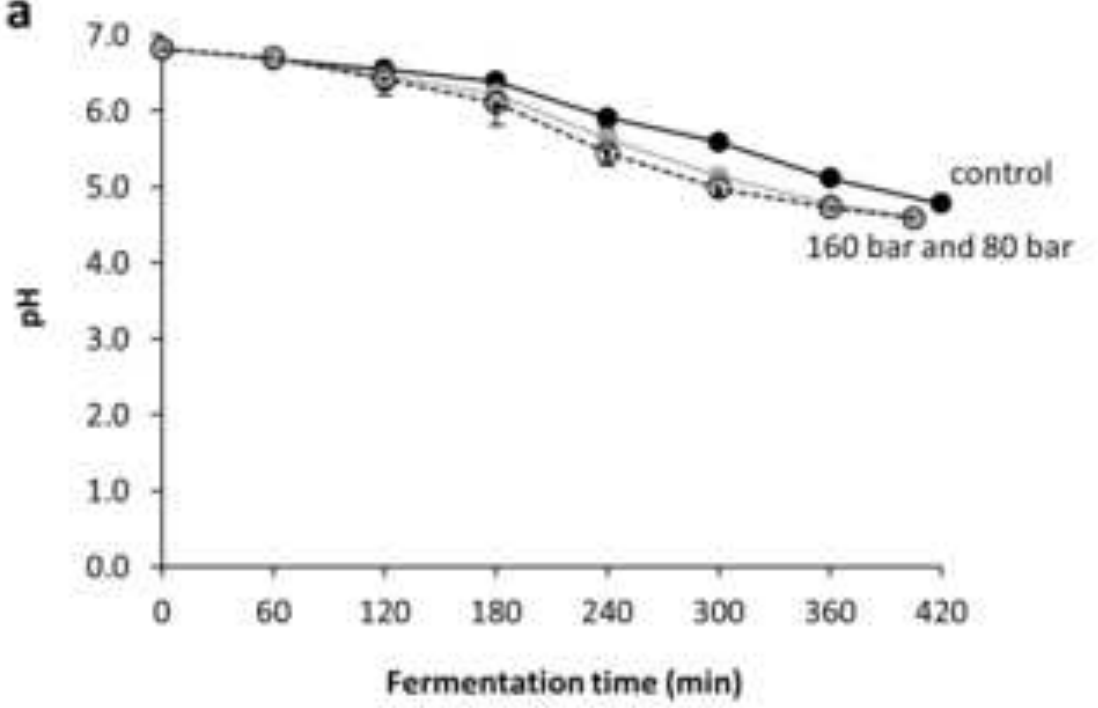

C

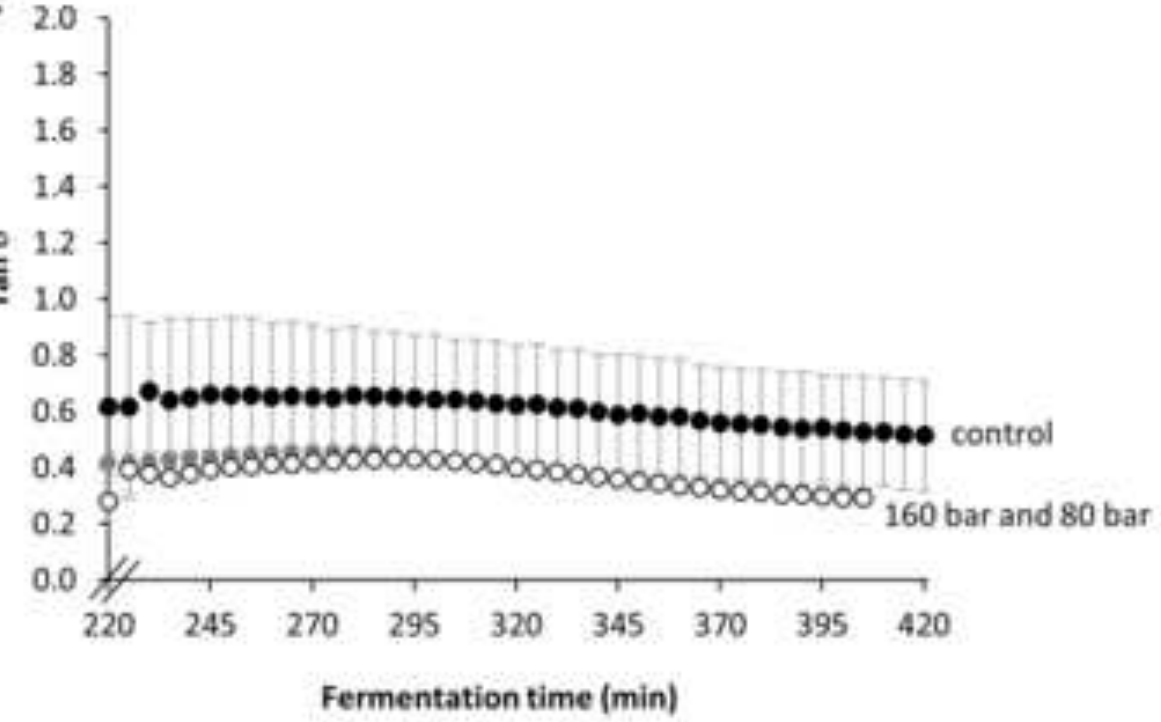

b

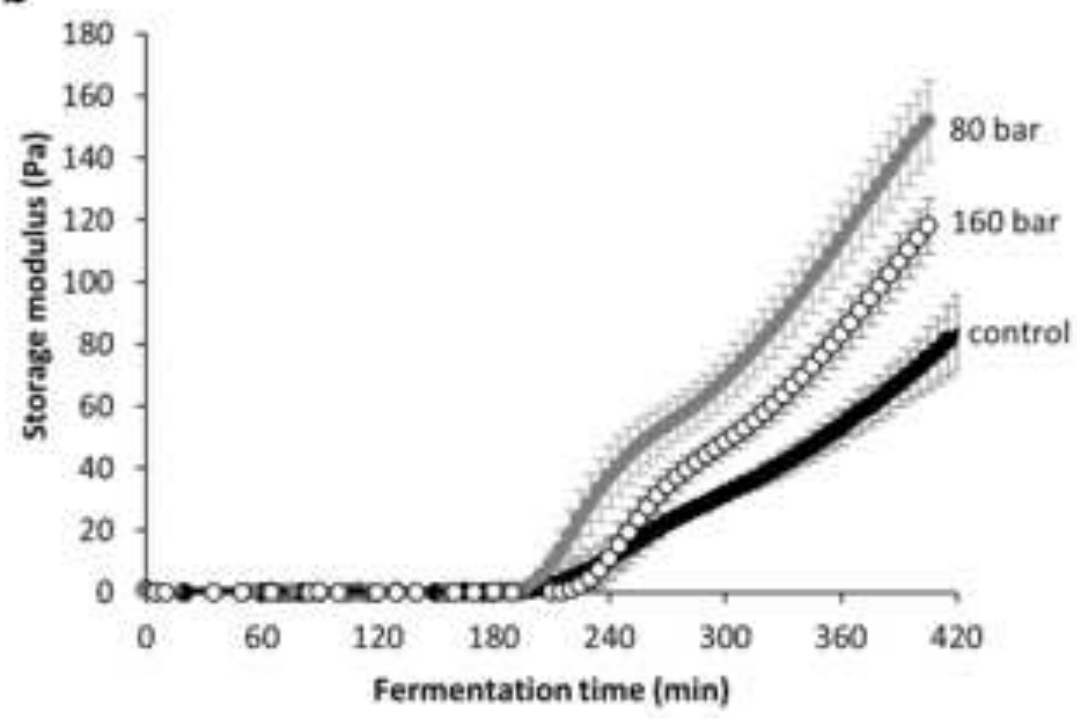

Figure 3. Changes in $\mathrm{pH}(\mathrm{a})$, storage modulus $\left(\mathrm{G}^{\prime}\right)(\mathrm{b})$ and loss tangent $(\tan \delta$ ) (c) during the fermentation of buffalo yoghurt produced from unhomogenised milk (control, $\bullet$ ), milk homogenised at 80 bar $(\bullet$ ) or milk homogenised at 160 bar (o). Each data point is the average of six measurements $(\mathrm{n}=6)$ in Figure $3 \mathrm{a}$ and the average of two measurements $(\mathrm{n}=2)$ in Figures $3 \mathrm{~b}$ and $\mathrm{c}$. The error bars are the standard deviation of the mean. 

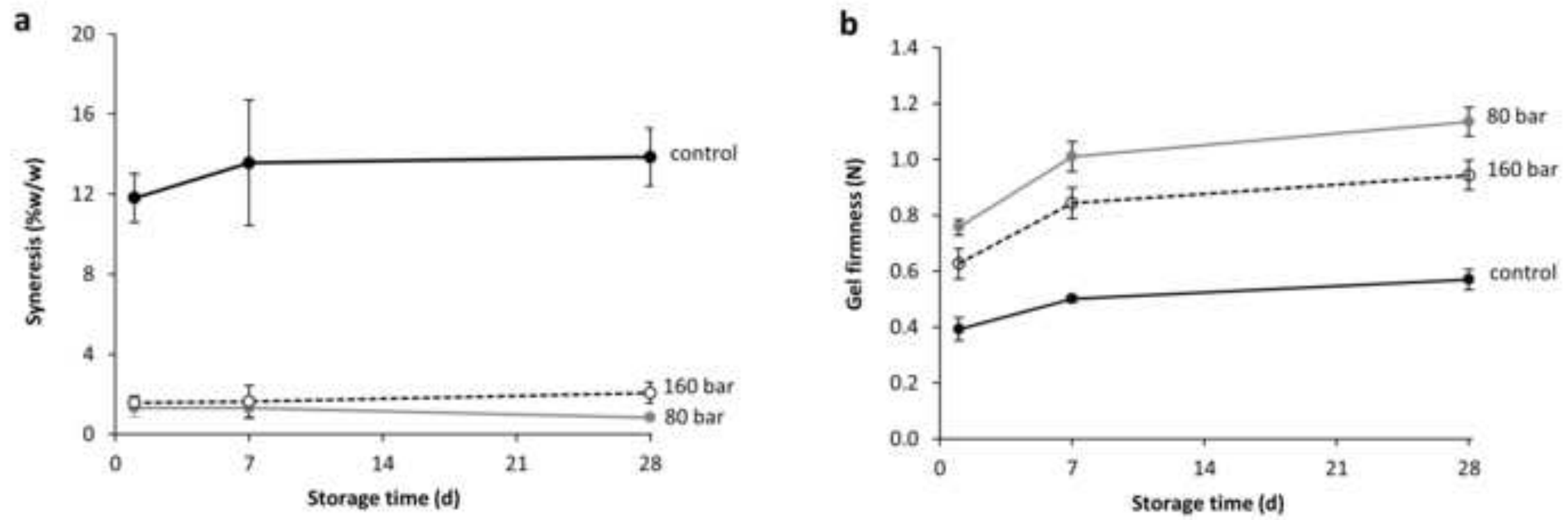

Figure 4. Changes in the syneresis (a) and gel firmness (b) of buffalo yoghurt produced from unhomogenised buffalo milk (control, $\bullet$ ), buffalo milk homogenised at 80 bar $(\bullet)$ or 160 bar $(0)$ during cold storage. Each data point is the average of six replicates $(\mathrm{n}=6)$. The error bars are the standard deviation of the mean. 
a

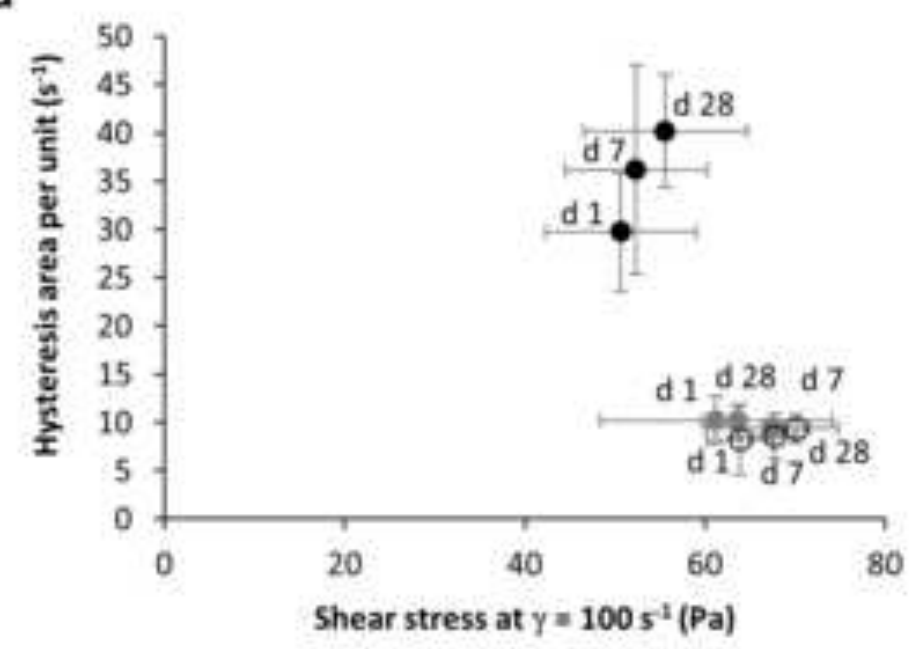

b

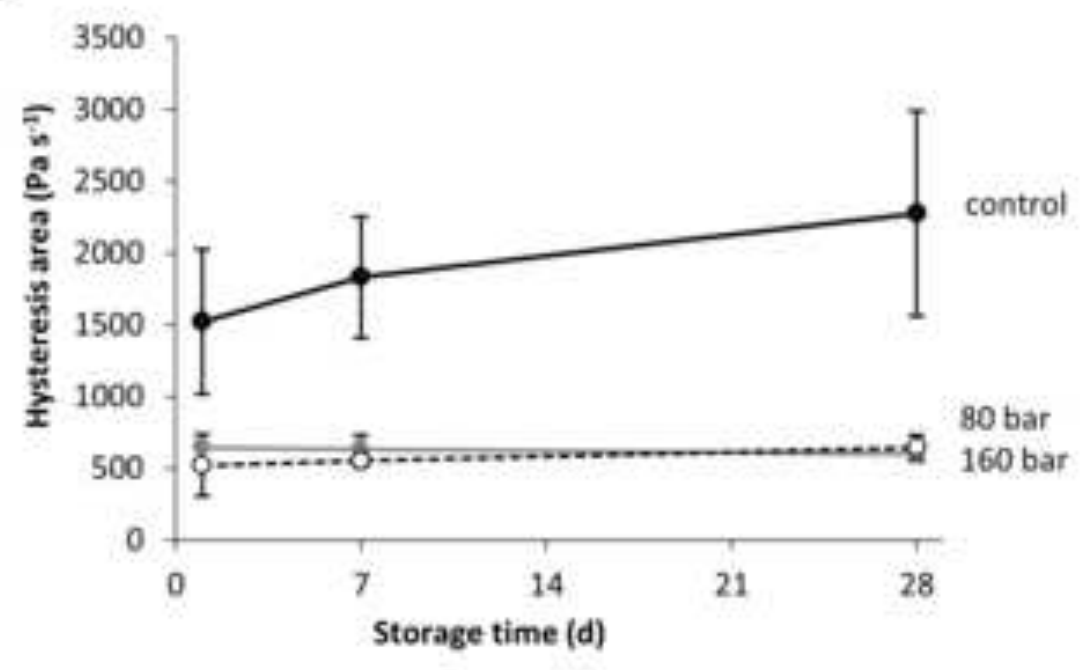

C

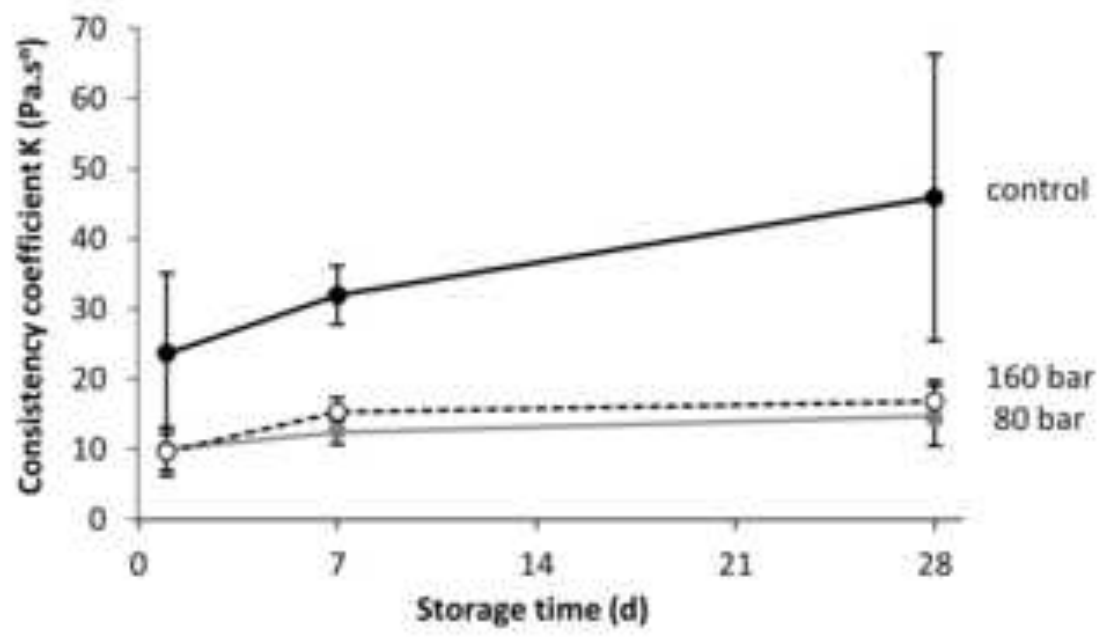

d

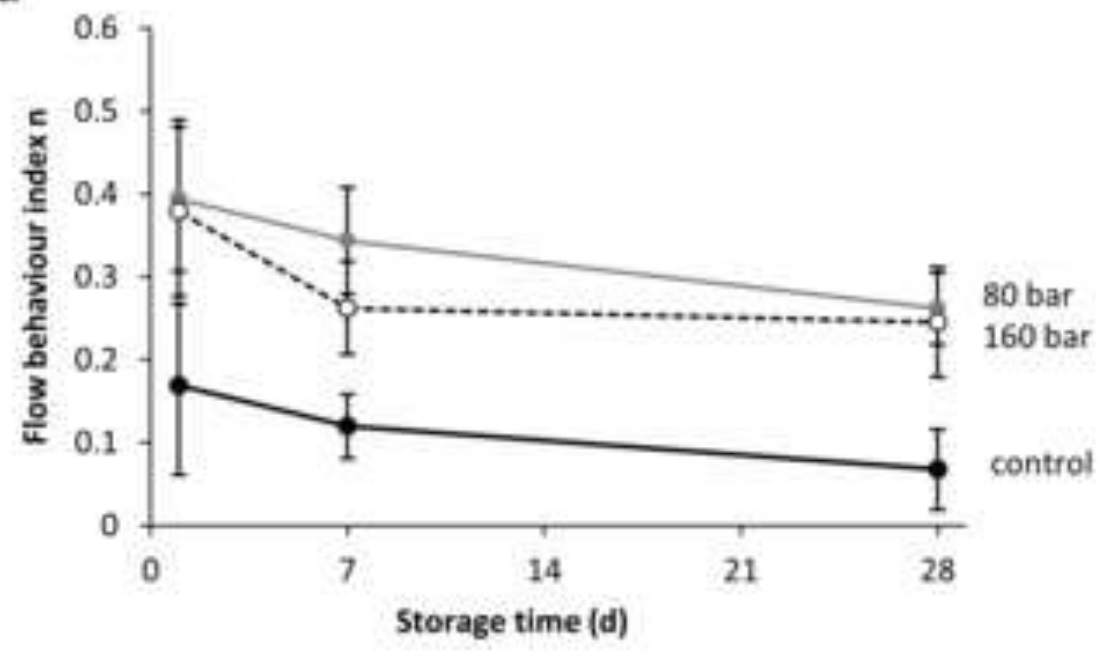

Figure 5. Changes in the stress-scaled hysteresis area (a), hysteresis area (b), consistency coefficient (c) and flow behaviour index (d) of buffalo yoghurt produced from unhomogenised buffalo milk (control, •), buffalo milk homogenised at 80 bar ( $\bullet$ ) or 160 bar (o) during cold storage. Each data point is the average of six replicates $(n=6)$ and the error bars are the standard deviation of the mean. 

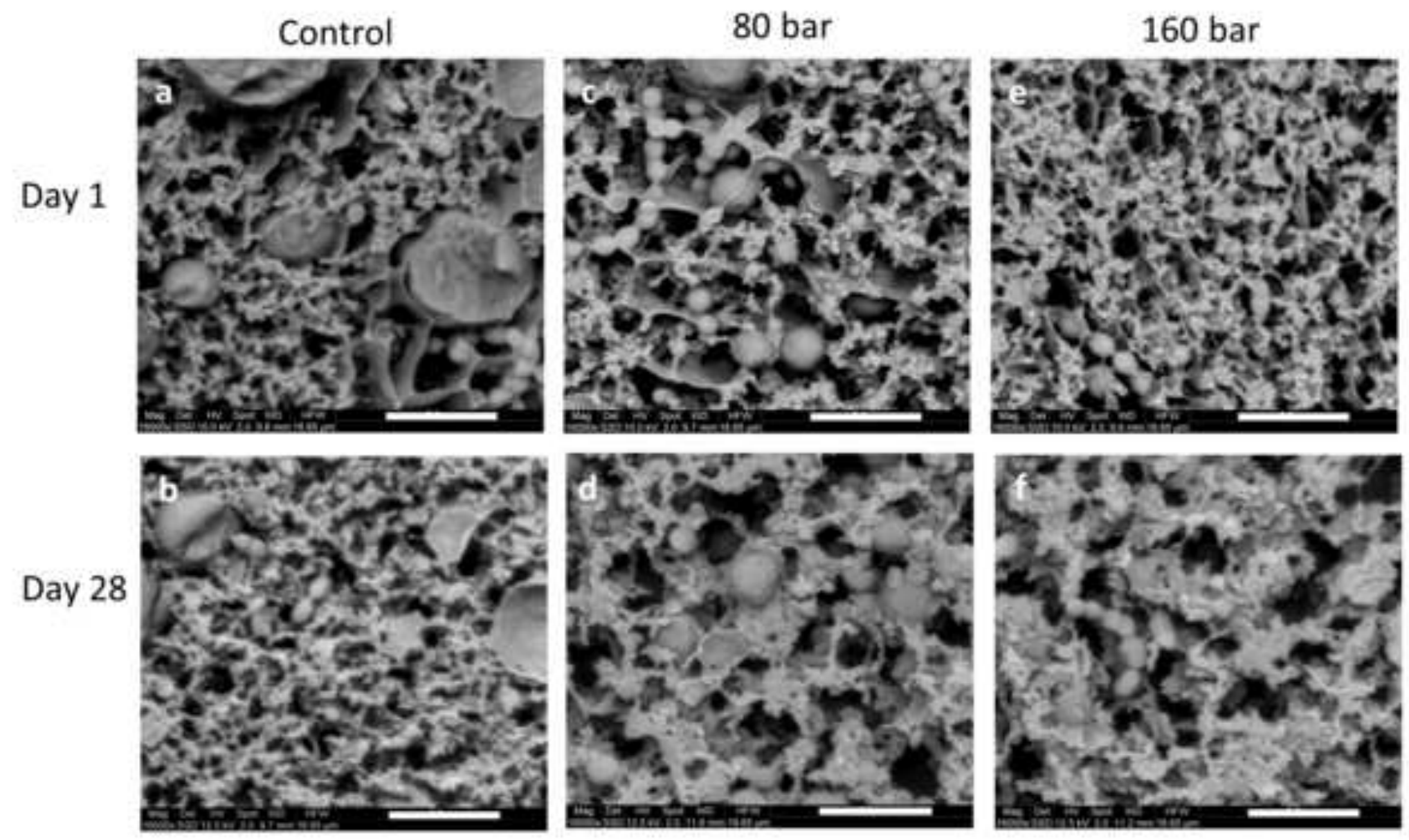

Figure 6. Microstructure of buffalo yoghurt produced from unhomogenised buffalo milk (control, a-b), buffalo milk homogenised at 80 bar (c-d) or 160 bar (e-f) at d 1 (upper images) and d 28 (lower images) of storage as observed by cryo-scanning electron microscopy. Images were captured using a solid state detector at $16000 \mathrm{x}$ magnification. The scale bars are $5 \mu \mathrm{m}$ in length. 
Control

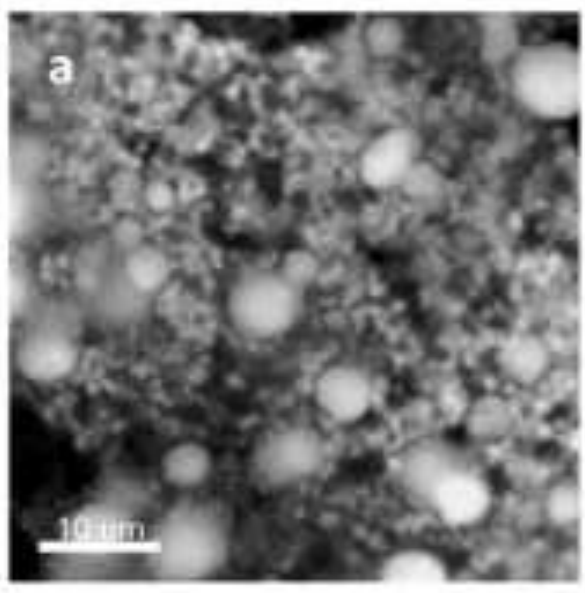

Day 1

Day 28

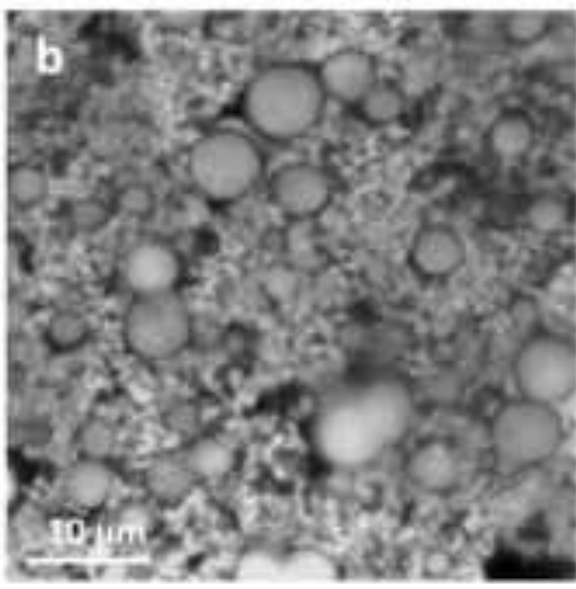

80 bar
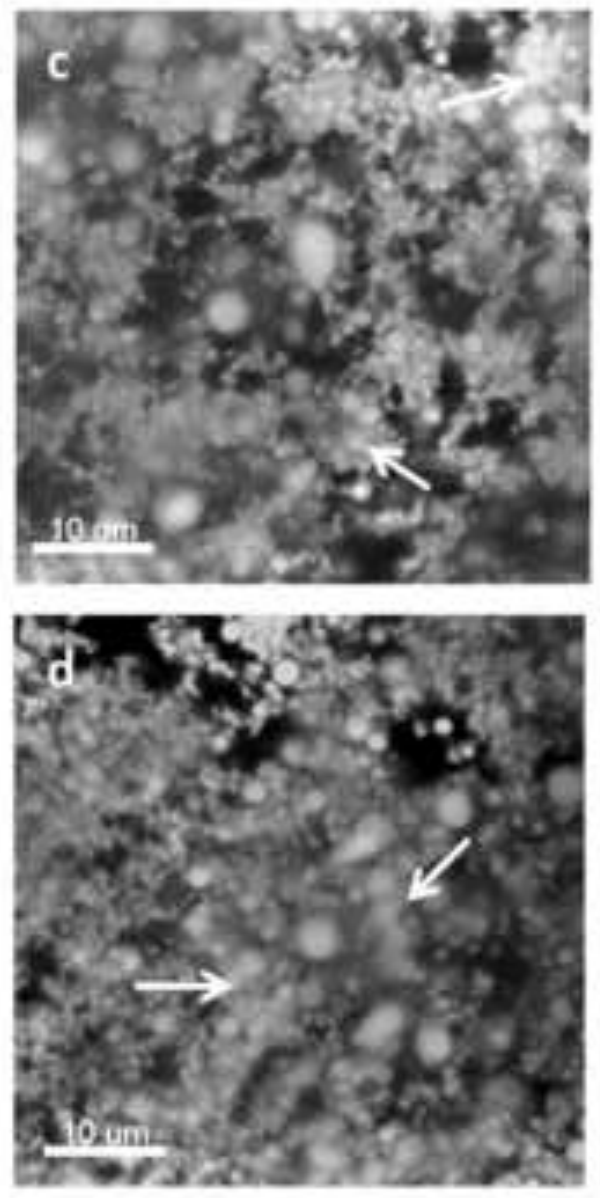

160 bar
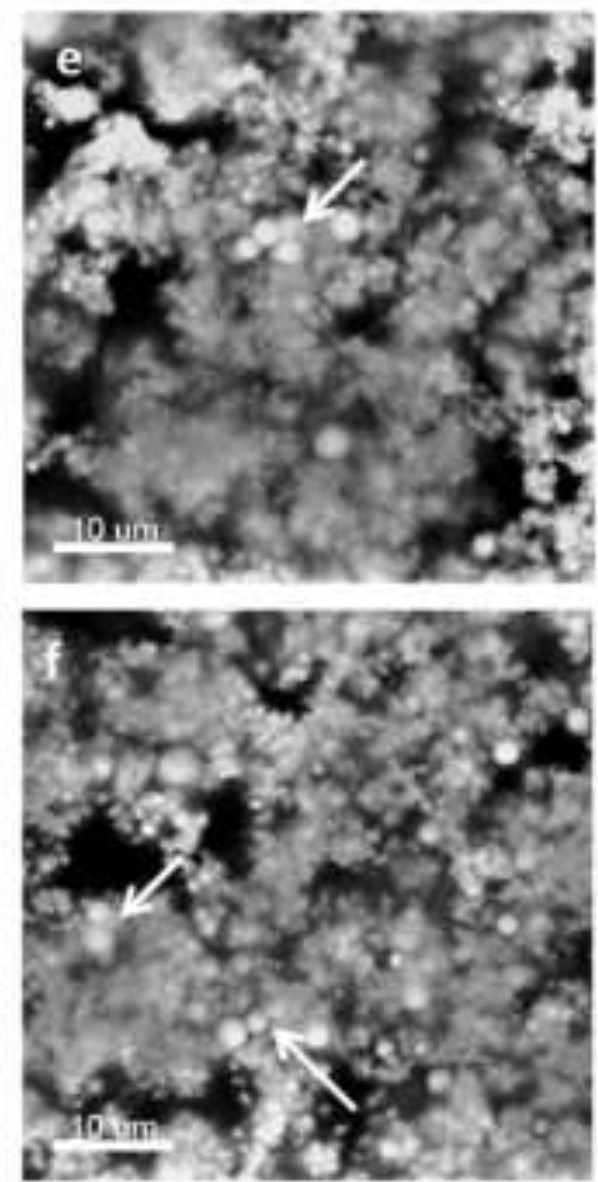

Figure 7. Microstructure of buffalo yoghurt produced from unhomogenised buffalo milk (control, a-b), buffalo milk homogenised at 80 bar (c-d) or 160 bar (e-f) at d 1 (upper images) and d 28 (lower images) of storage, as observed by confocal laser scanning microscopy. Images were captured using a $63 \mathrm{x}$ objective. The scale bars are $10 \mu \mathrm{m}$ in length. Arrows indicate the fat clusters induced by homogenisation. Please refer to the online edition for a color version of this figure. 
Figure 7 in colour for online publication

Click here to download high resolution image

Control
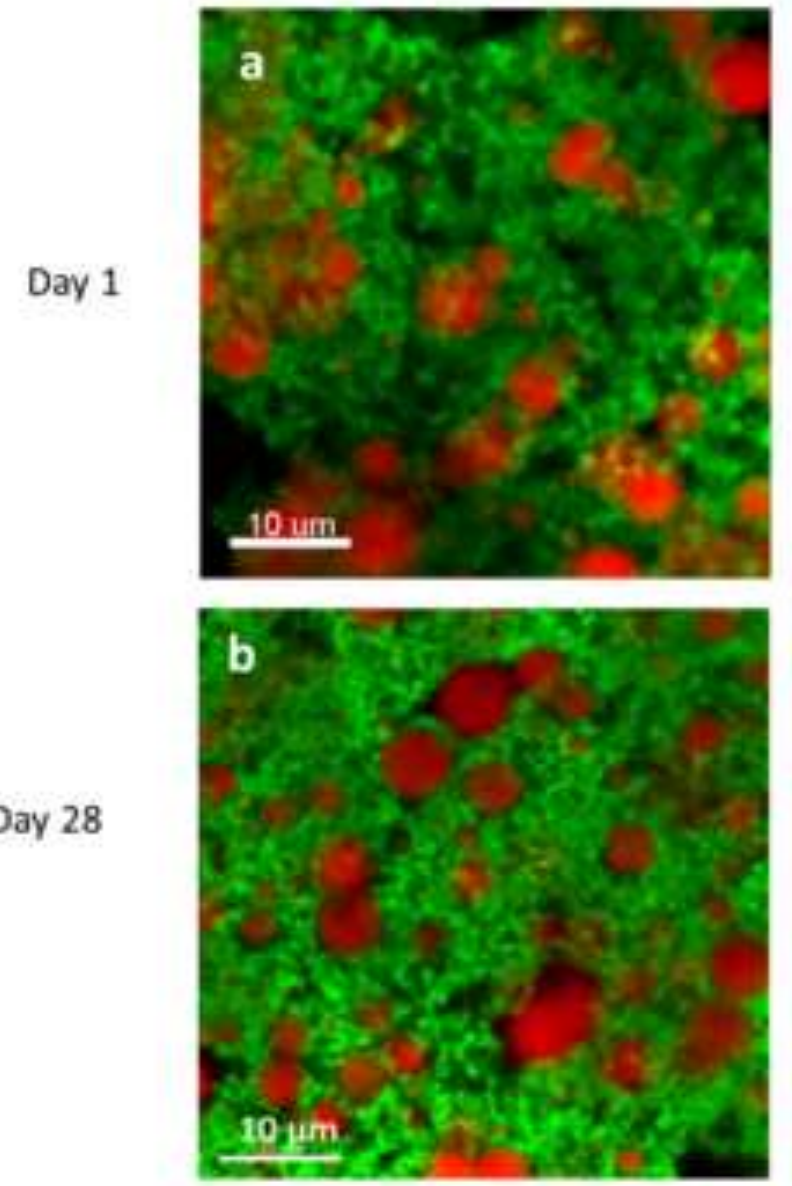

80 bar
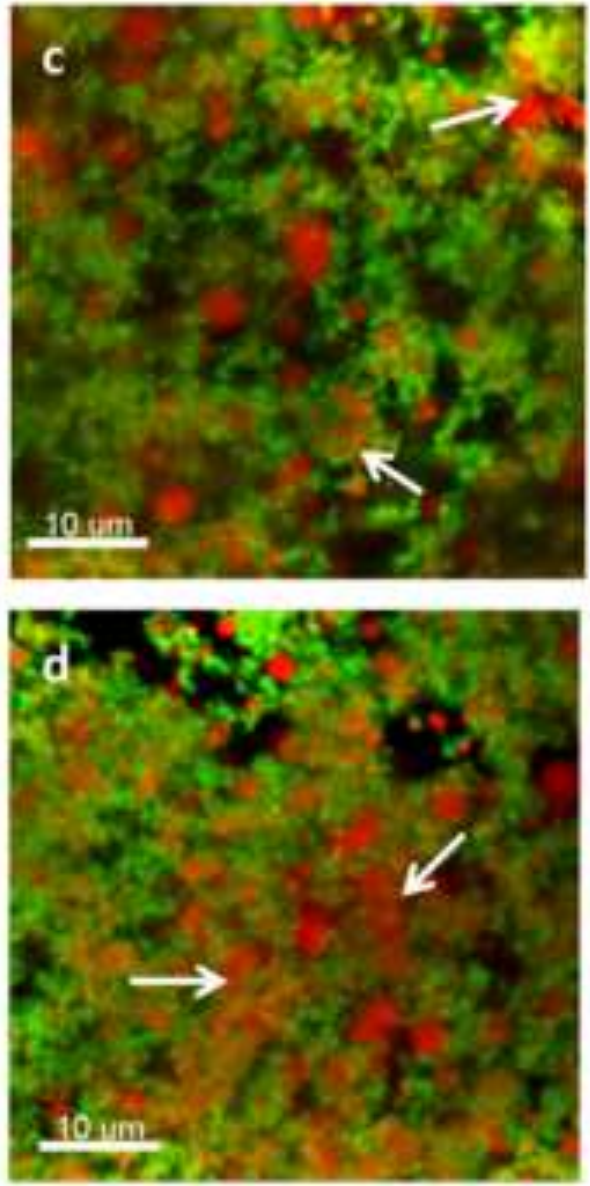

160 bar
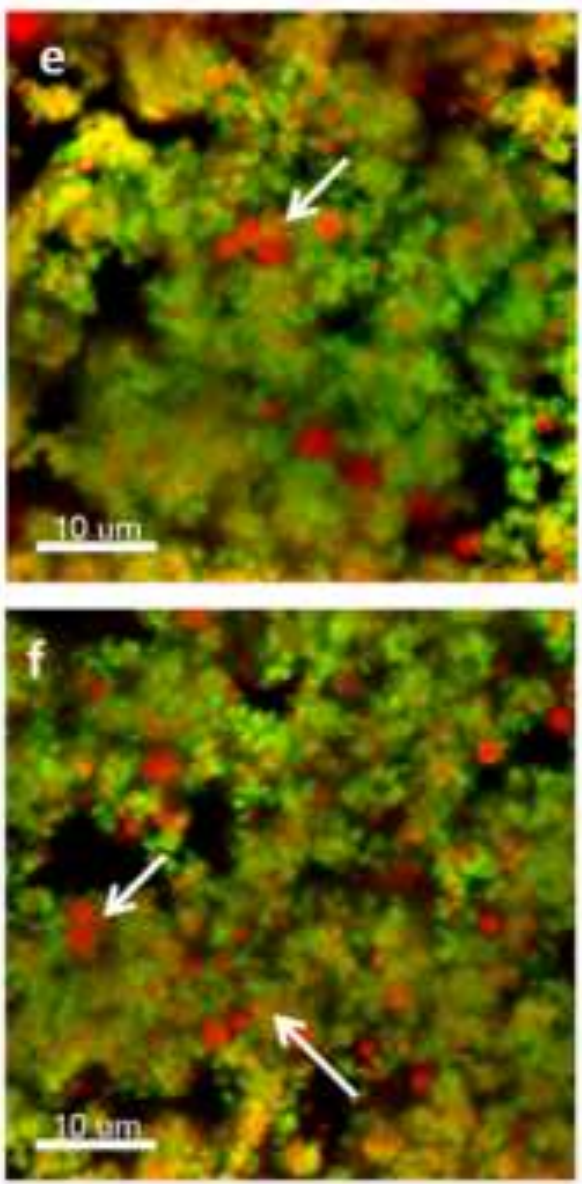

Figure 7 (online version). Microstructure of buffalo yoghurt produced from unhomogenised buffalo milk (control, a-b), buffalo milk homogenised at 80 bar (c-d) or 160 bar (e-f) at d 1 (upper images) and d 28 (lower images) of storage, as observed by CLSM. Nile Red stained fat appears red, FCF stained protein appears green and the black areas are serum pores. Images were captured using a $63 \mathrm{x}$ objective. The scale bars are $10 \mu \mathrm{m}$ in length. Arrows indicate the fat clusters induced by homgenisation. 
a
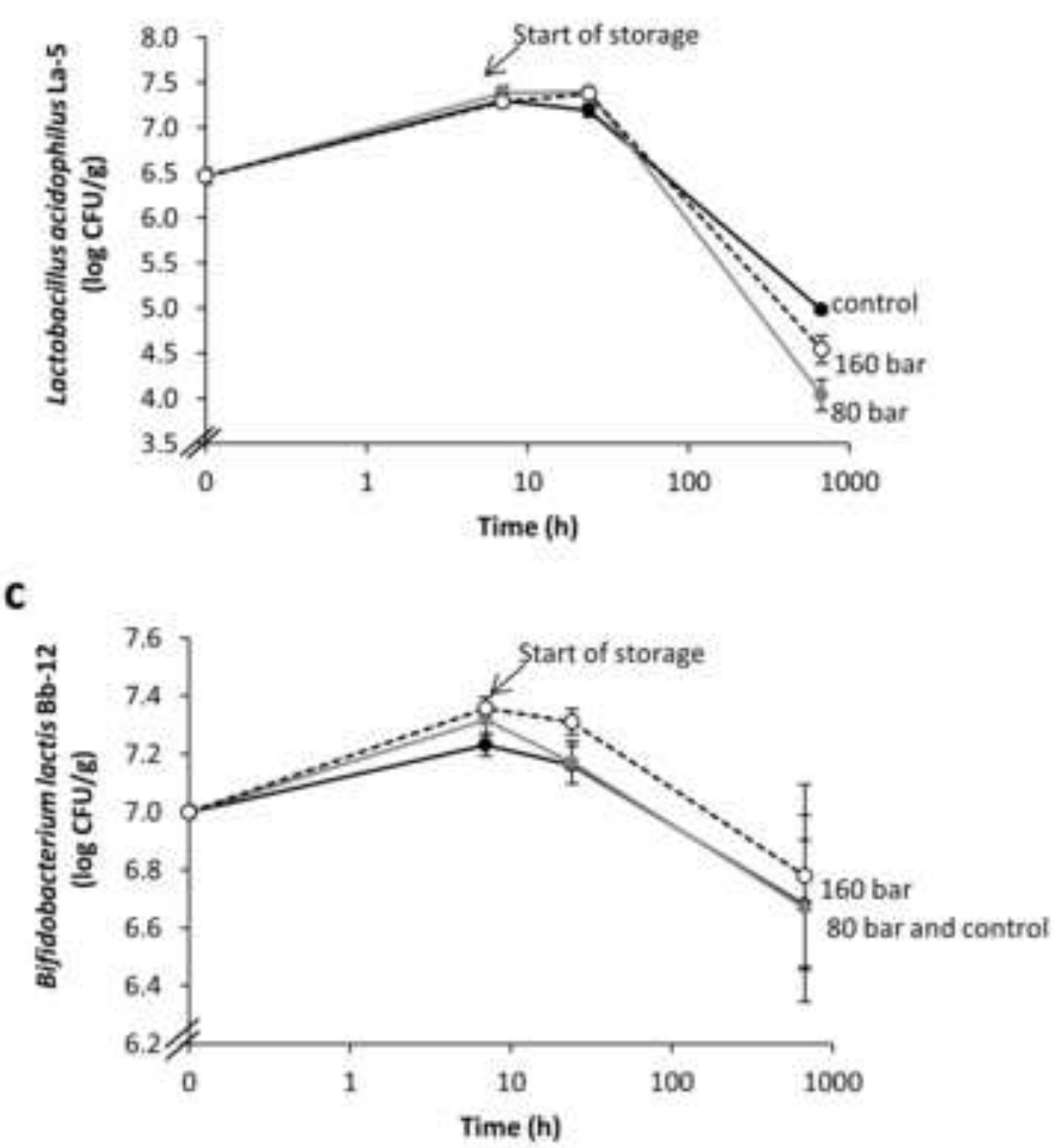

b

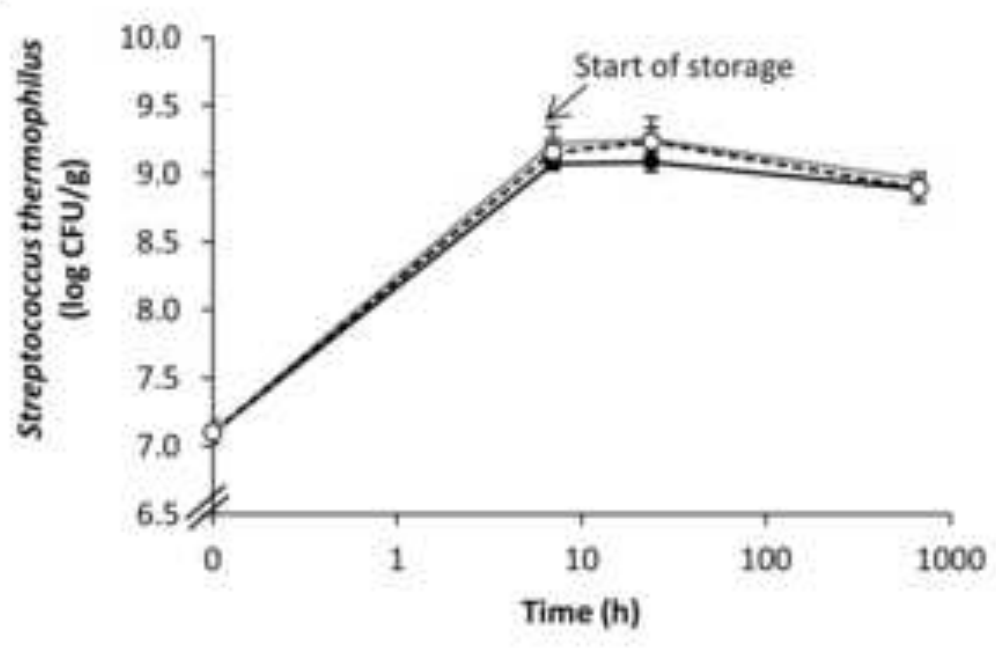

Figure 8. Growth and viability of Lactobacillus acidophilus La-5 (a), Streptococcus thermophilus (b) and Bifidobacterium lactis $B b-12$ (c) during the fermentation and storage of buffalo yoghurt produced from unhomogenised buffalo milk (control, $\bullet$ ), buffalo milk homogenised at 80 bar $(\bullet)$ or 160 bar ( $(0)$. Each data point is the average of four replicates $(\mathrm{n}=4)$ and the error bars are the standard deviation of the mean. 


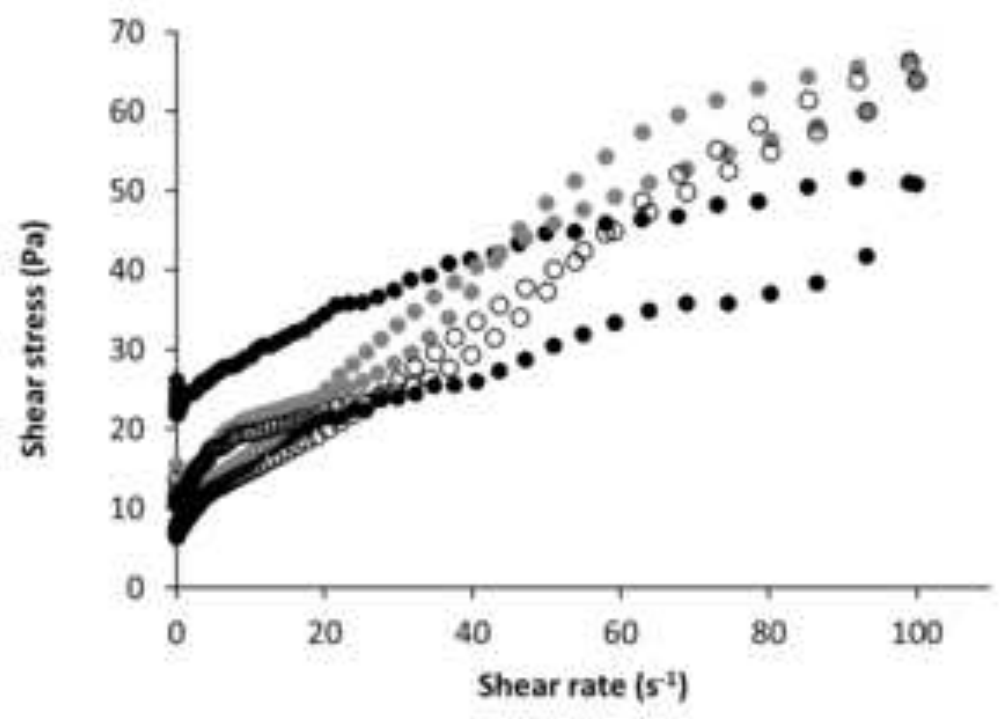

Supplementary A1. Flow curves at d 1 of storage of set style buffalo yoghurt produced from unhomogenised buffalo milk (control, $\bullet$ ), buffalo milk homogenised at 80 bar $(\bullet)$ or 160 bar (०). 